\title{
Improving Lake-Breeze Simulation with WRF Nested LES and Lake Model over a Large Shallow Lake
}

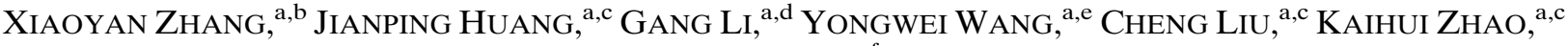 \\ XiNYu TAO, ${ }^{\mathrm{a}, \mathrm{c}}$ XIAO-Ming Hu, ${ }^{\mathrm{f}}$ AND XUHUi LeE ${ }^{\mathrm{a}, \mathrm{g}}$ \\ ${ }^{a}$ Yale-Nanjing University of Information Science and Technology Center on Atmospheric Environment/Key Laboratory of \\ Meteorological Disaster, Ministry of Education/International Joint Laboratory on Climate and Environmental Change/Collaborative \\ Innovation Center on Forecast and Evaluation of Meteorological Disasters, Nanjing University of Information Science and Technology, \\ Nanjing, China \\ ${ }^{\mathrm{b}}$ School of Atmospheric Science, Nanjing University of Information Science and Technology, Nanjing, China \\ ${ }^{\mathrm{c}}$ School of Applied Meteorology, Nanjing University of Information Science and Technology, Nanjing, China \\ ${ }^{\mathrm{d}}$ School of Mathematics and Statistics, Nanjing University of Information Science and Technology, Nanjing, China \\ ${ }^{\mathrm{e}}$ School of Atmospheric Physics, Nanjing University of Information Science and Technology, Nanjing, China \\ ${ }^{\mathrm{f}}$ Center for Analysis and Prediction of Storms and School of Meteorology, University of Oklahoma, Norman, Oklahoma \\ ${ }^{\mathrm{g}}$ School of Forestry and Environmental Studies, Yale University, New Haven, Connecticut
}

(Manuscript received 21 October 2018, in final form 15 May 2019)

\begin{abstract}
The Weather Research and Forecasting (WRF) Model is used in large-eddy simulation (LES) mode to investigate a lake-breeze case occurring on 12 June 2012 over the Lake Taihu region of China. Observational data from 15 locations, wind profiler radar, and the Moderate Resolution Imaging Spectroradiometer (MODIS) are used to evaluate the WRF nested-LES performance in simulating lake breezes. Results indicate that the simulated temporal and spatial variations of the lake breeze by WRF nested LES are consistent with observations. The simulations with high-resolution grid spacing and the LES scheme have a high correlation coefficient and low mean bias when evaluated against 2-m temperature, 10-m wind, and horizontal and vertical lake-breeze circulations. The atmospheric boundary layer (ABL) remains stable over the lake throughout the lake-breeze event, and the stability becomes even stronger as the lake breeze reaches its mature stage. The improved ABL simulation with LES at a grid spacing of $150 \mathrm{~m}$ indicates that the non-LES planetary boundary layer parameterization scheme does not adequately represent subgrid-scale turbulent motions. Running WRF fully coupled to a lake model improves lake-surface temperature and consequently the lake-breeze simulations. Allowing for additional model spinup results in a positive impact on lake-surface temperature prediction but is a heavy computational burden. Refinement of a water-property parameter used in the Community Land Model, version 4.5, within WRF and constraining the lake-surface temperature with observational data would further improve lake-breeze representation.
\end{abstract}

\section{Introduction}

Lake breezes, which are local circulations driven by the thermal contrast between lake and nearby land, are often observed near lakeshores under clear and calm weather conditions with strong solar radiation (Lyons 1972; Sills et al. 2011). Lake breezes may pose an important constraint on local weather and air quality in the lakeshore areas where population density is often highest (Rao et al. 2008; Gronewold et al. 2013). Usually convective activities are suppressed near lakeshores where lake breezes transport cooler and more humid air

Corresponding author: Jianping Huang, jianping.huang@noaa.gov from lake to land. However, severe storms related to deep convection are likely to be triggered inland at the lake-breeze frontal line where convergence tends to be strong (Laird et al. 2001). While air pollutant dispersion and transport patterns are modified by lake breezes, air quality deterioration can be alleviated to a large extent (Crosman and Horel 2010). On the other hand, air quality could be worsened if air pollutants concentrate along the convergence zone in and around urban areas where emissions are concentrated (Keen and Lyons 1978; McNider et al. 2018). Thus, improving lake-breeze predictions on a regional or local scale continues to represent a great interest to weather and air quality forecast and research. 


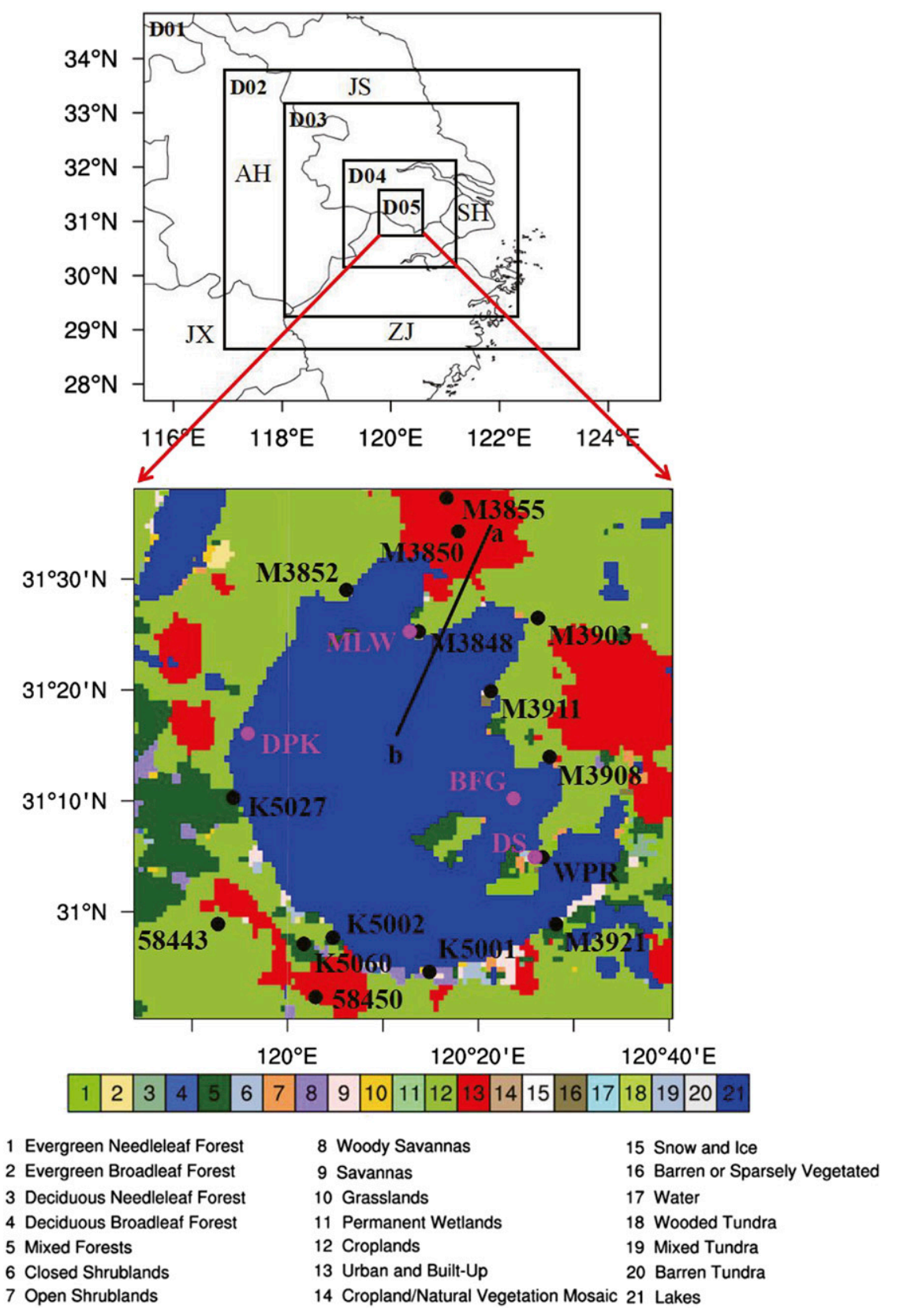

FIG. 1. (top) The WRF Model domain-five nested meshes with horizontal resolution of $12.15,4.05,1.35,0.45$ and $0.15 \mathrm{~km}$, and (bottom) land-use categories, locations of meteorological observational sites, eddy covariance monitoring sites (BFG, DPK, and MLW), and wind profiler radar (WPR; DS) along Lake Taihu over the innermost domain (D05). The outermost domain (D01) covers Jiangsu (JS), Shanghai (SH), north Zhejiang (ZJ), north Jiangxi (JX) and east Anhui (AH) Provinces. A line (line a-b) passing through the center point of the lake and Wuxi urban city in the innermost domain (D05, bottom panel) is selected for representing the cross section of vertical circulation.

Characterization of lake breezes is critical for improving numerical weather and air quality predictions in the areas near sizable lakes. The widely used parameters characterizing lake breezes include frequency, onset, cessation, duration, depth, and maximum penetration distance. Most of them have been widely studied through observational and numerical modeling studies (e.g., Lyons 1972; Sills et al. 2011; Kehler et al. 2016; Mariani et al. 2018). The results indicate that the characteristics of lake breezes vary greatly with lake properties, 
TABLE 1. Configuration of the WRF simulation.

\begin{tabular}{|c|c|c|c|c|c|}
\hline Domains & D01 & D02 & D03 & D04 & D05 \\
\hline Resolution (km) & 12.15 & 4.05 & 1.35 & 0.45 & 0.15 \\
\hline No. of grid points $($ lon $\times$ lat $)$ & $76 \times 67$ & $154 \times 145$ & $322 \times 313$ & $490 \times 481$ & $598 \times 589$ \\
\hline Microphysics & WSM3 & WSM3 & WSM3 & WSM3 & WSM3 \\
\hline Longwave radiation & RRTM & RRTM & RRTM & RRTM & RRTM \\
\hline Shortwave radiation & Dudhia & Dudhia & Dudhia & Dudhia & Dudhia \\
\hline Land surface model & CLM V4 & CLM V4 & CLM V4 & CLM V4 & CLM V4 \\
\hline Cumulus parameterization & Kain-Fritsch & Off & Off & Off & Off \\
\hline Planetary boundary layer & YSU & YSU & YSU & LES & LES \\
\hline Lake model & CLM V4.5 & CLM V4.5 & CLM V4.5 & CLM V4.5 & CLM V4.5 \\
\hline
\end{tabular}

such as lake size and depth. Typically, a large and deep lake has larger frequency, longer duration, higher lakebreeze depth, and stronger lake breezes than a small or middle-sized lake. For instance, the frequency of lake breezes in the southern Great Lakes regions with deep lakes was about $83 \%$ in June-August 2007 (Sills et al. 2011), much higher than that observed in the region near Lake Taihu (a shallow lake) in summer 2012 (13\%-40\%; Wang et al. 2017). However, in comparison with large and deep lakes, general features of lake breezes of small- and middle-sized lakes are not well quantified because of lack of a high-density monitoring network.

Physical parameterizations and grid spacing are the two important factors affecting numerical predictions of sea and lake breezes. Significant advancements have been made in model dynamics, treatment of physical processes, grid spacing, and computational efficiency since the numerical model was first applied to simulate sea breezes (Pearce 1955). However, uncertainties still remain in numerical predictions of sea and lake breezes (Fovell 2005; Zhang et al. 2005; Antonelli and Rotunno 2007; Freitas et al. 2007; Thompson et al. 2007; Dandou et al. 2009; Kala et al. 2010; Sills et al. 2011). Among the factors causing numerical prediction biases, physical parameterizations and grid spacing are two important ones. For instance, the existing planetary boundary layer (PBL) schemes tend to underpredict the PBL heights significantly over a lake or ocean surface and during nighttime (Dabberdt et al. 2004; Apel et al. 2010; Hu et al. 2010). The prediction biases are usually linked to simulation of a stable or neutral atmospheric boundary layer. Additionally, finescale structures of the atmospheric turbulence and interactions between lake breezes and geophysical variables are not explicitly resolved because of insufficient grid spacing employed in regional model simulations (Lambert 1974; Rao et al. 1999; Colby 2004).

Surface or near-surface water temperature is of primary importance for simulating lake/sea breezes. Temperature contrasts between land and water is the ultimate driving force of these thermal circulations, and this aspect of sea/lake breezes has received considerable attention.
However, the lake-surface temperature itself has not. While this issue is not a large concern for a large and deep lake whose surface temperature shows a small diurnal variation (Segal and Pielke 1985), it can be problematic for a shallow lake where large diurnal changes of lakesurface temperature occur (Deng et al. 2013; Wang et al. 2017).

Large-eddy simulation (LES) models are an ideal tool to quantify the impacts of geophysical variables on lake or sea breezes and to improve numerical prediction biases that are due to grid spacing and physical parameterization schemes. Crosman and Horel (2012) used a series of idealized LESs to examine the sensitivity of the sea and lake breezes to lake size, surface sensible heat flux, and atmospheric stability. They found that lake breezes show a similarity to the sea counterparts during the morning developmental phase, but a much weaker horizontal wind speed component and smaller inland penetration distance in the afternoon. Although stand-alone LES is a valuable tool, it is limited to idealized initial profiles, prescribed spatially homogeneous land surface and forcing, and periodic boundary layer conditions (e.g., Khairoutdinov et al. 2009; Heath et al. 2017).

The limitations of the traditional LES can be alleviated to some extent by using the LES nesting within a mesoscale model such as WRF (Heath et al. 2017). The advantage of the WRF nested LES lies in better representation of unresolved-scale motions and more realistic initial and lateral boundary conditions. The WRF nested LES has shown promising results in several meteorological research areas, such as PBL turbulence (Talbot et al. 2007), stratocumulus clouds (Zhu et al. 2010), and deep convection (Hanley et al. 2015; Stein et al . 2014; Heath et al. 2017). However, the WRF nested LES has not been applied to simulate lake- or sea-breeze development. The stable boundary layer over lakes during lake-breeze development imposes a challenge to the WRF nested-LES modeling framework.

Lake Taihu is a large and shallow lake (average depth of $1.9 \mathrm{~m}$ and total area of $2400 \mathrm{~km}^{2}$ ) in the Yangtze River delta in China. Previous studies have found that, for the 

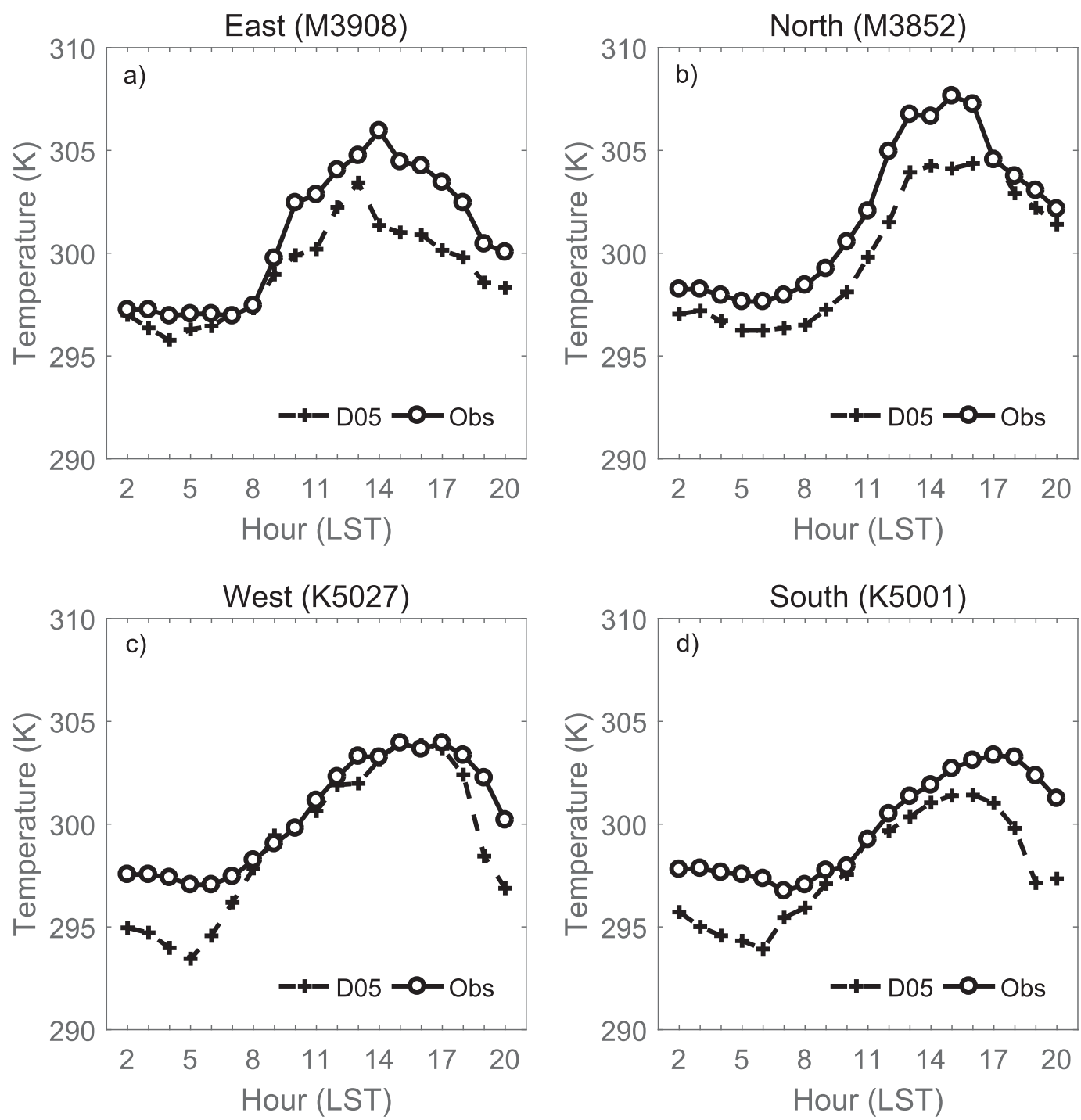

FIG. 2. Time series of simulation-observation comparison for 2-m air temperature at four sites on the (a) east (M3908), (b) north (M3852), (c) west (K5027), and (d) south (K5001) sides of the lake from domain D05. The time period covers 0200-2000 LST 12 Jun 2012 (from 1800 UTC 11 Jun to 1200 UTC 12 Jun 2012).

large-sized lakes with width in excess of $80 \mathrm{~km}$, the intensity of lake breezes tends to resemble that of sea breezes (Crosman and Horel 2012). As compared with sea breezes or lake breezes over large and deep lakes, few studies have been conducted on lake breezes over shallow lakes. Recently, Wang et al. (2017) presented one full year of observational data (2012) to characterize the general characteristics of lake breezes over Lake Taihu. The observational analysis indicates that the lake breeze at Lake Taihu occurs less frequently (e.g., average value of $12 \%-$ $17 \%$ in 2012), has a weaker lake-breeze wind speed (a range of $\left.1.5-3.3 \mathrm{~m} \mathrm{~s}^{-1}\right)$ and a shorter duration $(3.5 \mathrm{~h})$ when compared with lake breezes at deep lakes such as Lake Michigan (Lyons 1972; Comer and McKendry 1993; Laird et al. 2001). Such observational analysis forms a base for better understanding the lake-breeze formation mechanism and for improving numerical predictions. However, some important features, such as maximum penetration distance, are still not well quantified.

In this study, the WRF nested LES is used to investigate a typical lake-breeze case occurring over Lake Taihu and fill the abovementioned knowledge gap. The Community Land Model, version 4.5 (CLM V4.5), lake model (Oleson et al. 2013; Gu et al. 2015) is also employed to compute lake-surface temperature and improve the calculation of temperature gradients near the lake shorelines. The simulations are evaluated with highresolution monitoring data (Wang et al. 2017). The nested 


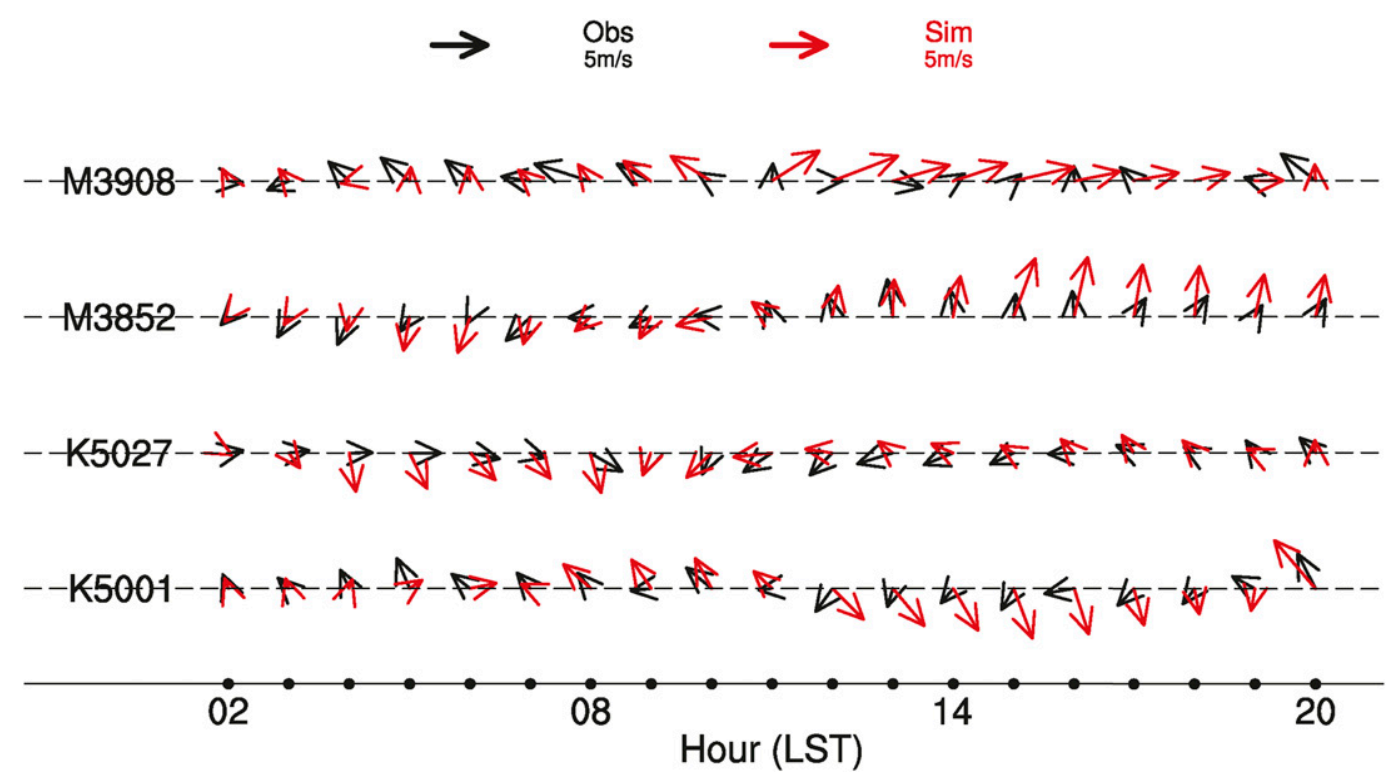

FIG. 3. Time series of simulation-observation comparison for 10-m wind vector at four sites on the east (M3908), north (M3852), west (K5027), and south (K5001) sides of the lake.

domain simulations without LES setting are compared with those with LES settings to examine the impact of grid spacing and the PBL parameterization on surface temperature, intensity, and depth of lake breezes. The specific objectives of this study are 1) to improve the lakebreeze predictions by using the WRF nested LES with a lake model and 2) to quantify the impact of grid spacing and lake model on lake-breeze predictions.

\section{Method and data}

\section{a. Brief description of the WRF nested LES}

The state-of-the-art numerical schemes (i.e., higherorder time and advection schemes), massively parallel computation design, and diversified grid nesting skills allow the WRF Model to extend its capability beyond the mesoscale to perform LES. The numerical schemes used in the WRF Model for LES applications differ substantially from those used in traditional LES studies (Moeng 1984). The former uses a finite-differencing scheme to solve fully compressible equations whereas the latter uses the Fourier spectrum method to solve incompressible equations. Several LES intercomparisons indicate that the first- and second-order turbulence statistics are not sensitive to the numerical schemes (Nieuwstadt et al. 1993; Andren et al. 1994).

In the WRF nested LES, a sub-filter-scale (SFS) model is used to calculate the contribution of unresolved-scale turbulent motion to the total flux or variance. The relative contribution of unresolved-scale turbulence motion is larger in the coarse-grid domain than in the fine-grid domain. The SFS model is able to calculate the amount of heat and momentum fluxes transported by the SFS turbulent motion (Moeng et al. 2007). Accurate representation of unresolved-scale motion by a SFS model is the key that allows the WRF to perform LES. There are two SFS models in the WRF Model for calculating turbulence closure: the 3D Smagorinsky (1963) and the 1.5-order turbulent kinetic energy (TKE) (Stull 1988) closures. This study uses the 1.5-order TKE closure for the SFS turbulent stress of scalars. The nonlinear backscatter and anisotropic (NBA) model (Kosović 1997; Mirocha et al. 2010) is used to calculate the SFS turbulent stress for momentum and shows the potential of performing coarse-resolution LES with comparative performance to a higher-resolution version. For instance, the WRF nested-LES method has been used to study Hurricane Katrina at grid spacing of $333.3 \mathrm{~m}$ by Green and Zhang (2015). These results are encouraging and motivating further use of the NBA SFS model in realworld cases.

There are two options for running LES with the WRF Model. The first one is to perform simulations with the WRF code using idealized LES settings, that is, single thermodynamic profile, spatially homogeneous forcing and period boundary layer conditions. The second one represents the case that the LES domains are nested within a regional-scale domain, allowing for more realistic initial and boundary conditions. In this study, the latter is selected and LESs are performed with two nesting domains. 


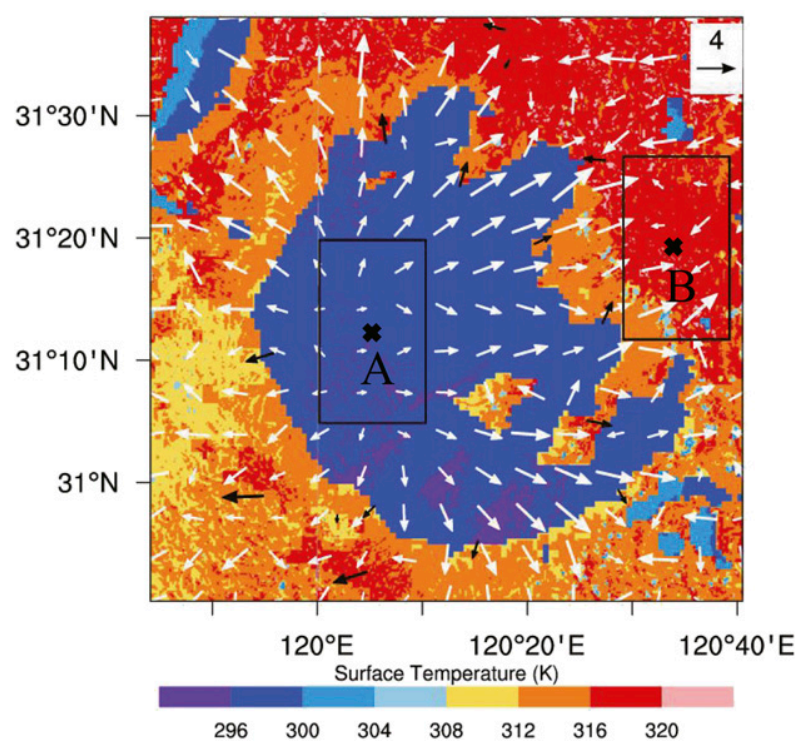

FIG. 4. A comparison of observed (black arrows) and predicted (white arrows) winds together with simulated surface temperature at 1300 LST (0500 UTC) 12 Jun. Two black-outlined boxes and their center points (A and B) are selected to represent the areas of the lake and land, respectively, and to present the profiles of potential temperature.

The lake model is a one-dimensional thermal diffusion model embedded in the CLM V4.5. The water temperature is predicted by solving a mass and energy balance equation in which the vertical transfer of heat is simulated by eddy conductivity and convective mixing (Hostetler and Bartlein 1990). The inputs driving the lake model include air temperature, water vapor, air vapor pressure, wind speed, solar radiation, and longwave atmospheric radiation, which are predicted by the WRF. The surface temperature predicted by the lake model is sent back to the WRF during the simulations.

\section{b. Configurations of the WRF nested LES}

WRF, version 3.7.1, was employed with 5 two-way nested domains (Fig. 1). The horizontal spacing from the outermost (domain 1; D01) to the innermost (domain 5; D05) domain is $12.15,4.05,1.35,0.45$, and $0.15 \mathrm{~km}$, respectively. The corresponding numbers of grid points are $76 \times 67,154 \times 145,322 \times 313,490 \times 481$, and $598 \times 589$. The outermost domain covers Jiangsu (JS), Shanghai (SH), north Zhejiang (ZJ), north Jiangxi (JX), and east Anhui (AH) Provinces, while the innermost domain includes Lake Taihu and the surrounding major cities such as Suzhou (east side), Huzhou (south), Yixing (west), and Wuxi (north). There are 76 terrain-following layers defined from the surface to the 100-hPa level, with 34 layers within the first $1500 \mathrm{~m}$ above ground level (AGL). Thirty arc-second (approximately $1 \mathrm{~km}$ ) landuse and land-cover data derived from MODIS measurements were used by the WRF-LES simulations in all of the domains.

Initial conditions are used in D01, D02, and D03, whereas LES settings are used in D04 and D05. The initial conditions and lateral boundary conditions (LBCs) for D01 are provided by the National Centers for Environmental Prediction Climate Forecast System, version 2 (CFSv2), reanalysis data with a horizontal resolution of $0.5^{\circ}$ and an interval of $6 \mathrm{~h}$. The LBCs of
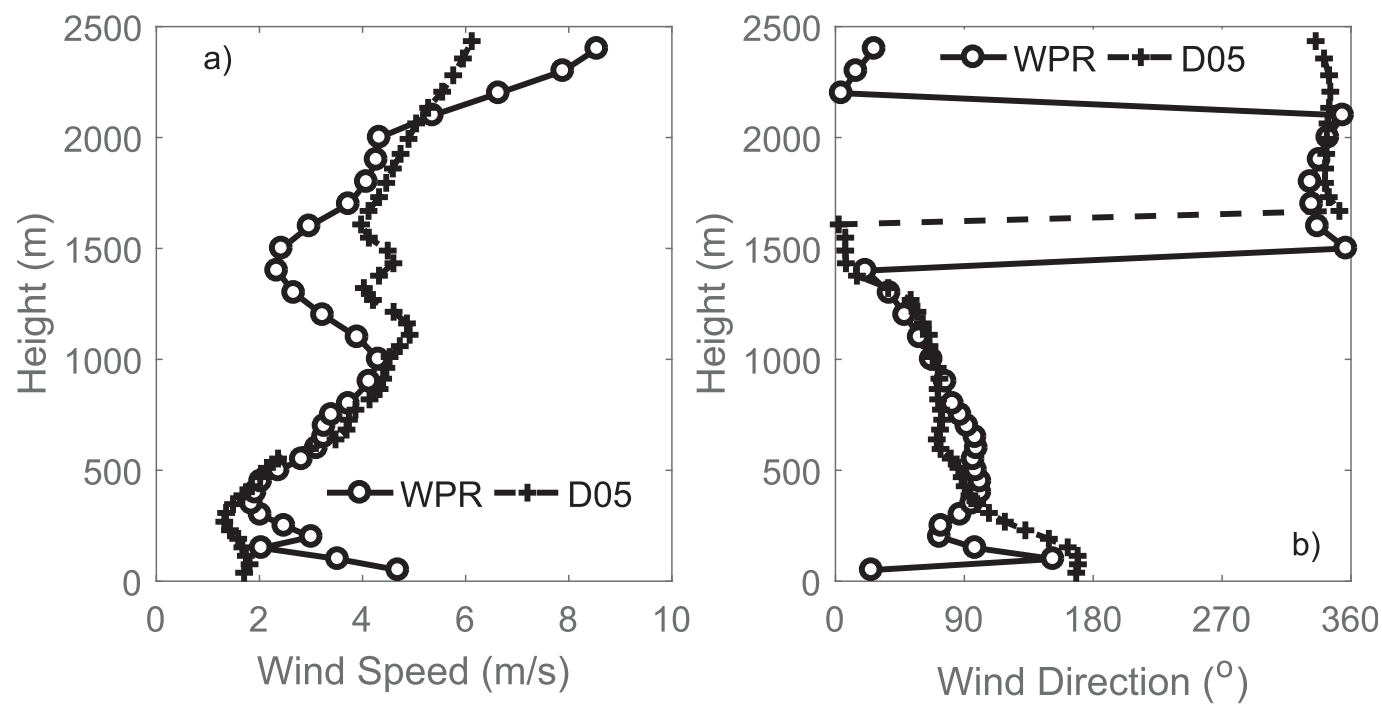

FIG. 5. A comparison of observed (WPR) and simulated vertical profiles of (a) wind speed and (b) wind direction at 1400 LST (0600 UTC) 12 Jun 2012. 


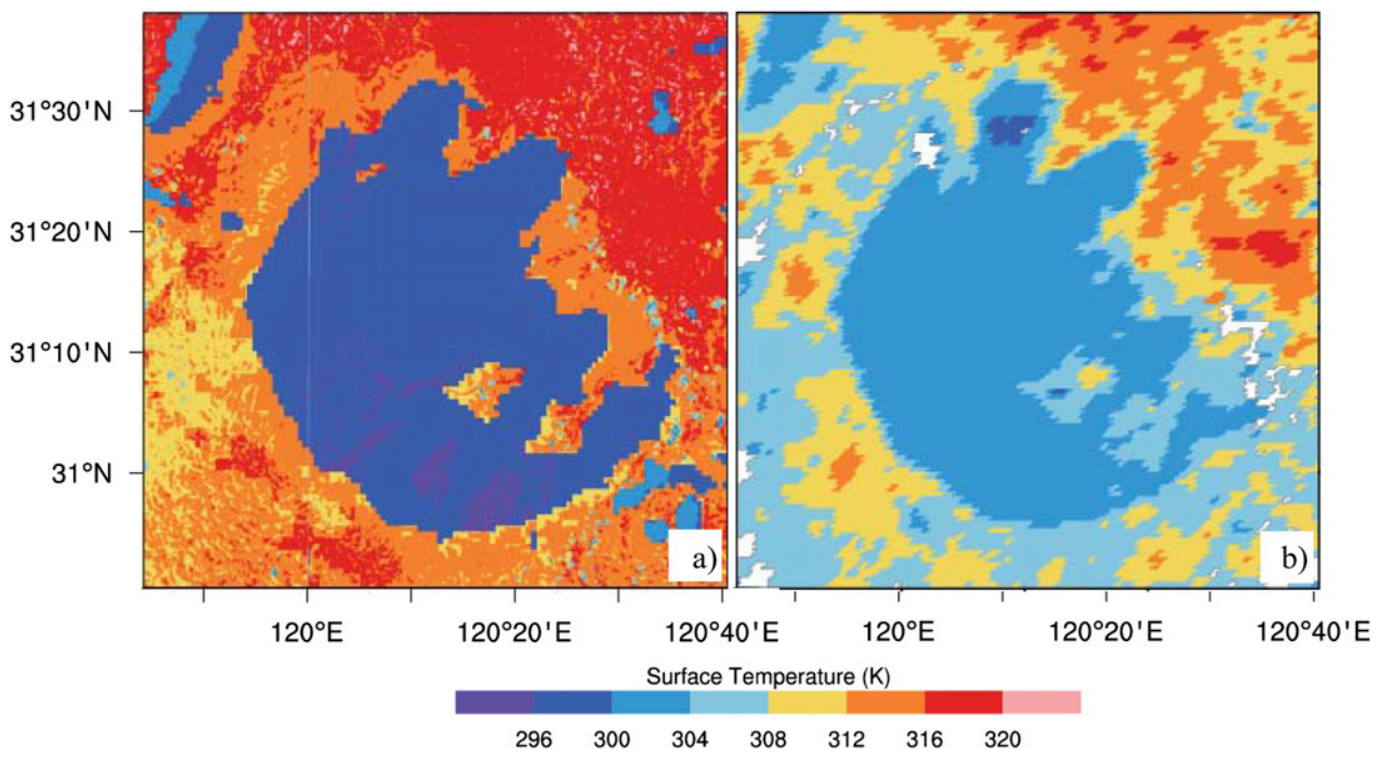

FIG. 6. (a) Simulated and (b) satellite-retrieved surface temperature (K) at 1330 LST (0530 UTC) 12 Jun 2012.

the other four domains are provided dynamically by their respective outer-domain simulations. The physics schemes used in these domains are summarized in Table 1 . All of the domains use the WRF single-moment 3-class simple ice (WSM3) microphysics scheme (Hong et al. 2004), the Rapid Radiative Transfer Model (RRTM; Mlawer et al. 1997) for longwave radiation, the Dudhia shortwave radiation scheme (Dudhia 1989), and the CLM V4 land surface model (Oleson et al. 2010; Lawrence et al. 2010). There are two exceptions for the physics parameterization schemes. First, the KainFritsch cumulus parameterization scheme is only applied to D01 (Kain and Fritsch 1993). A convective parameterization is typically required when grid spacing is larger than $10 \mathrm{~km}$ (Wong et al. 2013). Second, the Yonsei University (YSU) PBL scheme (Hong et al. 2006) is used in D01, D02 and D03, whereas LES closure is used in D04 and D05.

The CLM V4.5 lake model is used to simulate lakesurface temperature. The average depth of Lake Taihu (i.e., $2 \mathrm{~m}$ ) is utilized in the simulations. The depth of the first layer is set to $0.1 \mathrm{~m}$, and then the depth gradually increases from the second layer to the tenth layer at the bottom. The initial lake-surface temperature is defined with the CFSv2 reanalysis data, and water temperatures at different layers in the lake are initialized through the linear interpolation between lake-surface temperature and lake-bottom temperature, which is set to a constant (i.e., $277 \mathrm{~K}$ in this study). During the simulation, a Crank-Nicholson thermal diffusion solution is used to compute the lake temperature of each layer (Oleson et al. 2004). A total of 10 layers are defined for solving the vertical distribution of water temperature. The heat flux exchange between the lake and soil is calculated based on the energy transfer equation at the lake bottom.

\section{c. Observational data}

The observational data used for model evaluations include hourly air temperature at $1.5 \mathrm{~m} \mathrm{AGL}, 10-\mathrm{m}$ wind speeds and wind direction, water temperature, vertical profiles of wind and satellite-retrieved surface temperature. There were 15 surface automated weather stations available for temperature and wind measurements around Lake Taihu. Three eddy-covariance monitoring sites (BFG, DPK, and MLW; see Fig 1 for their locations) over the lake provide water temperature and solar radiation (BFG) (Lee et al. 2014). An on-site wind profiler radar (WPR) located in DS station with a sampling frequency of $6 \mathrm{~min}$ provides vertical profile of wind speed and wind direction up to a height of $5000 \mathrm{~m}$. The measurement biases of WPR data for wind speed and wind direction were less than $1 \mathrm{~m} \mathrm{~s}^{-1}$ and $10^{\circ}$, respectively. Locations of these stations are shown in Fig. 1.

Quality control measures are taken to ensure the quality of all the observational data. Four of the surface observational sites (M3851, M3854, M3907, and M3912) on land are excluded because of missing data and are not shown in Fig. 1. Meanwhile, data outliers are excluded based on the values associated with extreme events and the law of spatial and temporal continuities. For example, observed temperature higher than $45.0^{\circ} \mathrm{C}$ or lower than $-10.0^{\circ} \mathrm{C}$ or wind speed higher than $30.0 \mathrm{~m} \mathrm{~s}^{-1}$ is not included in our analysis and model evaluations. In addition, observed winds are not used for the model 

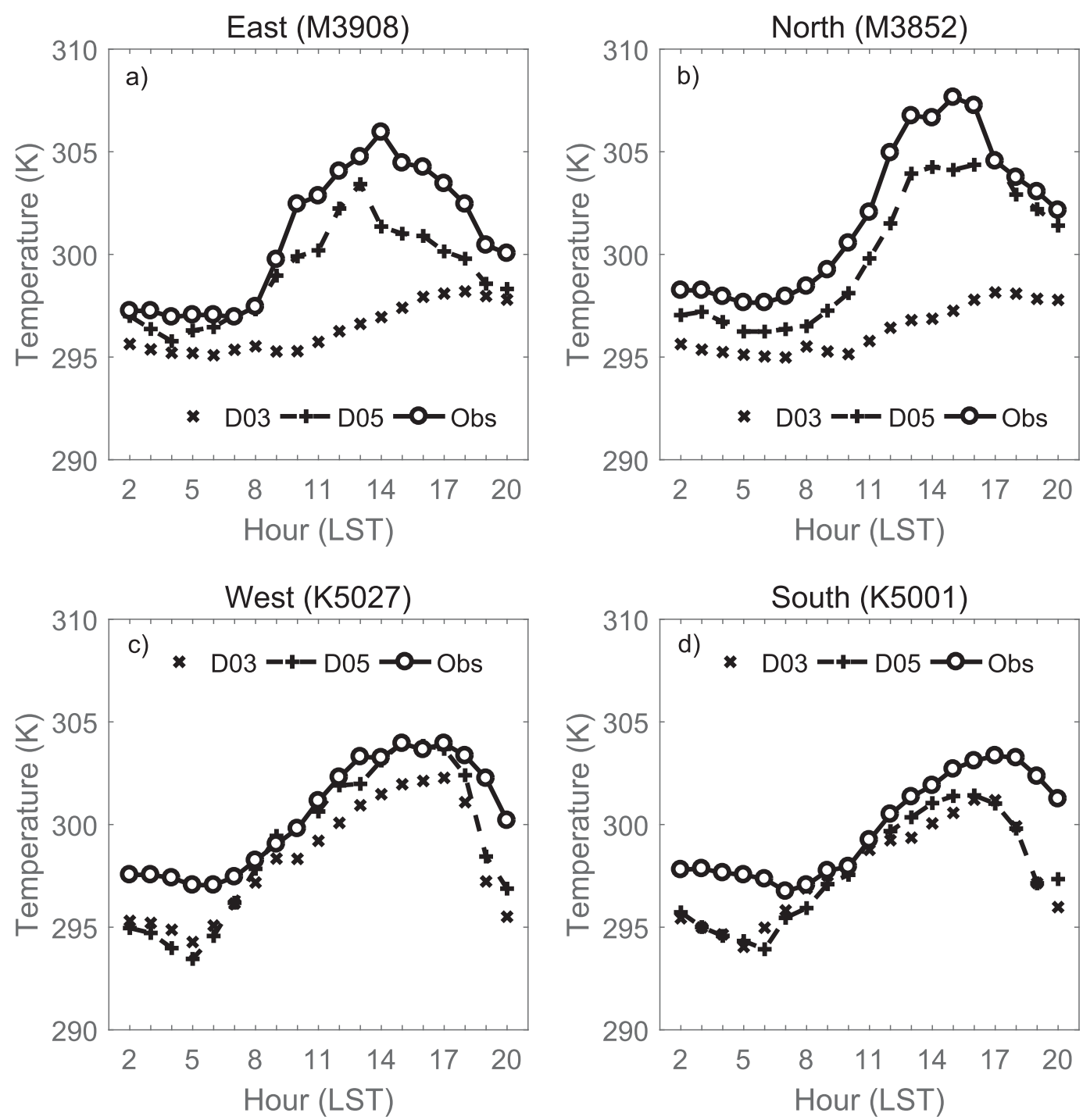

FIG. 7. Time series comparison of observations and simulations in domain D03 and domain D05 for 2-m air temperature at four sites on the (a) east (M3908), (b) north (M3852), (c) west (K5027), and (d) south (K5001) sides of the lake.

evaluation when wind speed lower than $0.1 \mathrm{~m} \mathrm{~s}^{-1}$ lasted for more than $1 \mathrm{~h}$ because such low wind speed is likely caused by instrument errors (Wang et al. 2017). Low winds with speed less than $0.1 \mathrm{~m} \mathrm{~s}^{-1}$ and duration less than $1 \mathrm{~h}$ are not excluded (Wang et al. 2017).

\section{Results}

\section{a. Evaluation of LES modeling of the lake breeze}

WRF nested-LES simulations were performed from 0200 local standard time (LST) [ $8 \mathrm{~h}$ ahead of coordinated universal time (UTC)] 12 June to 2000 LST 13 June 2012 to simulate the temporal and spatial variations of a lake breeze. On this day, the Yangtze River delta region where Lake Taihu is located was under the influence of a high pressure system with its center at Shanghai $\left(21.26^{\circ} \mathrm{N}\right.$, $121.35^{\circ} \mathrm{E}$ ), China. The weather was characterized by weak geostrophic winds (less than $4.0 \mathrm{~m} \mathrm{~s}^{-1}$ ) in the morning, strong solar radiation (with the maximum value of $794.9 \mathrm{~W} \mathrm{~m}^{-2}$ around solar noon at BFG site) and clear sky; these conditions were conducive to development of the lake-breeze circulation.

Surface temperature is critical for lake-breeze simulations. Figure 2 shows a time series comparison of the simulated 2-m air temperature in D05 with observations at four land sites near the lakeshore. These sites are located on the four sides of the lake and their locations 

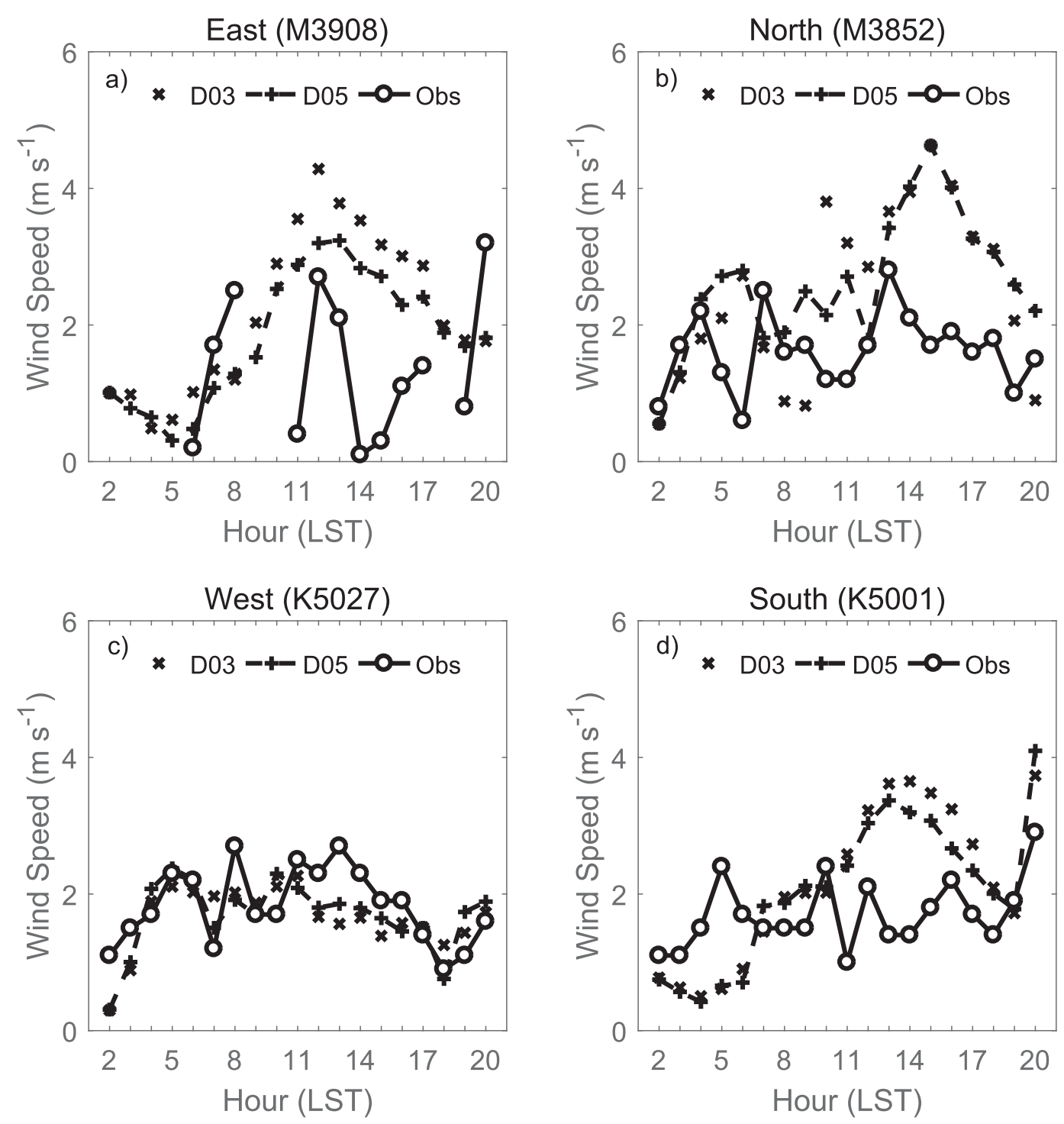

FIG. 8. As in Fig. 7, but for 10-m wind speeds.

are shown in Fig. 1b. It is noted that the initial temperatures are underestimated at southern and western lakeshores. The largest underestimation reaches $2.0 \mathrm{~K}$ on the western shore at site K5027 (see location in
Fig. 1). The underpredictions are likely attributed to various factors, including lack of long-enough spinup time, inappropriate model setup or physics parameterizations, and inaccurate representation of underlying

TABLE 2. The statistical evaluation (correlation coefficients $C_{r}$, mean bias MB, and root-mean-square errors RMSE) of measured and predicted 2-m air temperature $T, 10-\mathrm{m}$ wind speed (WSP), and $U$ and $V$ wind components among domains D05, D04, D03, D02, and D01 during the simulation period on 12 Jun 2012.

\begin{tabular}{|c|c|c|c|c|c|c|c|c|}
\hline & \multicolumn{4}{|c|}{$C_{r}$} & \multicolumn{2}{|c|}{ MB } & \multicolumn{2}{|c|}{ RMSE } \\
\hline & $T$ & WSP & $U$ & $V$ & $T(\mathrm{~K})$ & $\mathrm{WSP}\left(\mathrm{m} \mathrm{s}^{-1}\right)$ & $T(\mathrm{~K})$ & $\mathrm{WSP}\left(\mathrm{m} \mathrm{s}^{-1}\right)$ \\
\hline $\mathrm{D} 05$ & 0.94 & 0.36 & 0.49 & 0.53 & 1.78 & 0.92 & 3.10 & 1.89 \\
\hline D04 & 0.92 & 0.32 & 0.42 & 0.45 & 1.96 & 1.05 & 3.12 & 1.94 \\
\hline D03 & 0.92 & 0.30 & 0.38 & 0.46 & 2.42 & 1.23 & 3.18 & 2.06 \\
\hline D02 & 0.90 & 0.24 & 0.35 & 0.52 & 2.47 & 1.28 & 3.21 & 2.11 \\
\hline D01 & 0.90 & 0.19 & 0.15 & 0.50 & 2.51 & 1.37 & 3.25 & 2.17 \\
\hline
\end{tabular}



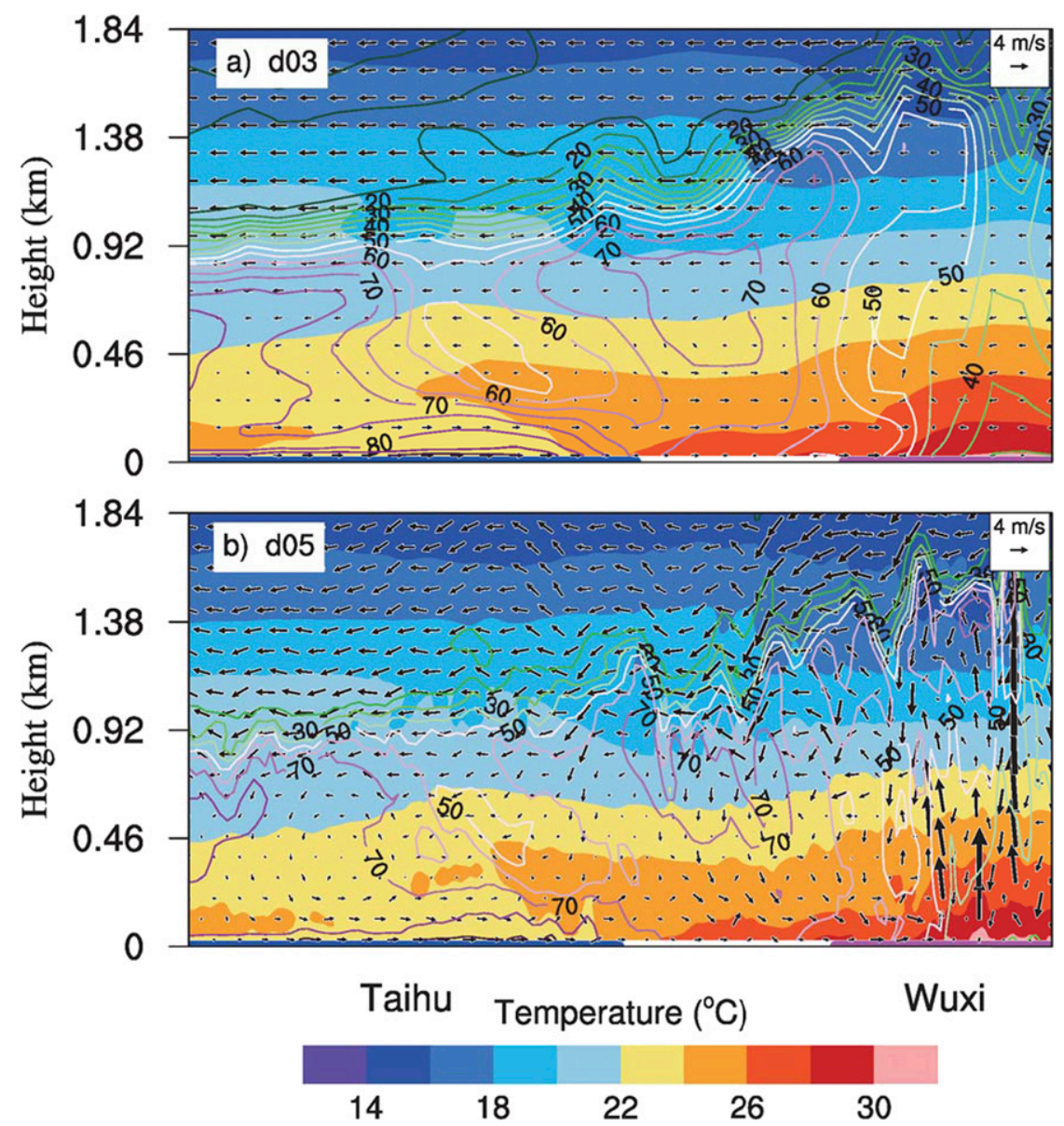

FIG. 9. Cross sections of wind field (arrows; vertical velocity $W$ component multiplied by 5 for highlighting the vertical circulation when plotting wind vectors), air temperature (shaded), and relative humidity (contours) from (a) domain D03 and (b) domain D05 at 1300 LST (0500 UTC) 12 Jun 2012. The lake surface is represented by the solid blue line, and city Wuxi is marked by the solid magenta line.

geographic data in the domains. Among them, underlying geographic data that are not represented properly by the WRF nested LES in the domain (i.e., D03) is likely the important one. This indicates that finescale underlying geographic data is critical to simulate the local winds. It is noted that the WRF nestedLES model adjusts itself through time quite well. It captures the increasing temperature and follows the general trend of observations closely after sunrise. Surprisingly, the WRF nested LES is still not able to reproduce the local maximum temperature at the east and north sites, even with a horizontal grid spacing of $150 \mathrm{~m}$. The mean $2-\mathrm{m}$ air temperature is underestimated by 1.2 , $1.5,1.8$, and $2.0 \mathrm{~K}$ at the east, north, west, and south sides, respectively. Exclusion of local anthropogenic heat source from the surface energy budget equation and prediction biases of water temperature are likely part of the reason for such biases.
Figure 3 shows a simulation-observation comparison of wind vectors at the same four sites as presented in Fig. 2. Observations show that the lake breeze developed at western and northern lakeshores (e.g., sites K5027 and M3852) around 1000-1100 LST, about $1 \mathrm{~h}$ earlier than the time at other two lakeshore sites. The synoptic-scale easterly winds likely support the early development of the lake breeze on the western lakeshore. The lakebreeze duration observed at the southern lakeshore is 3-4h, which is much shorter than that at the northern lakeshore (about 9h). The observed lake-breeze wind speed is $0.1-2.9 \mathrm{~m} \mathrm{~s}^{-1}$, much weaker than that observed at deep lakes such as Lake Michigan, where the highest lake-breeze wind speed is typically $6 \mathrm{~m} \mathrm{~s}^{-1}$ (Comer and McKendry 1993). The simulations show pretty good agreement with observations at the western shore in terms of onset time, duration, and the lake-breeze wind speed. This is likely related to the relatively flat 


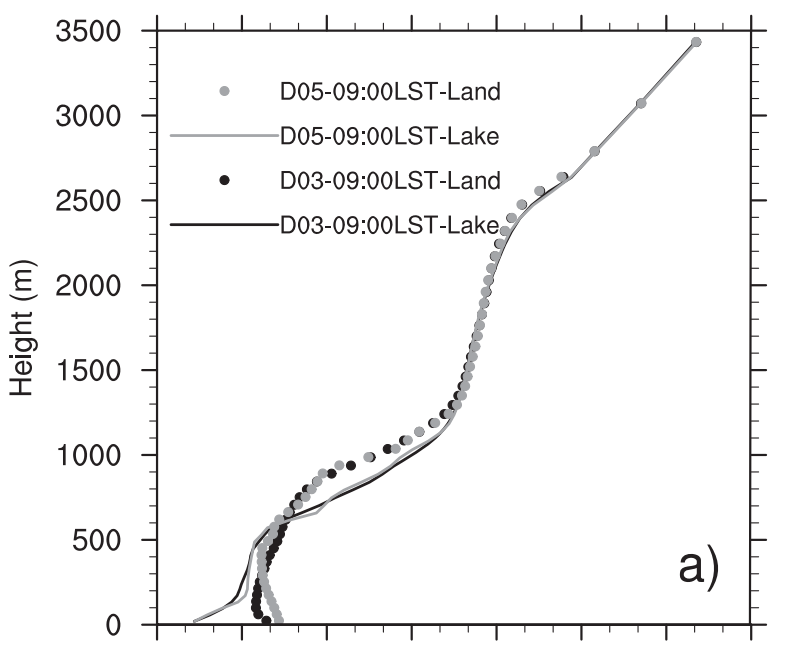

294.0297 .0300 .0303 .0306 .0309 .0312 .0315 .0 Potential Temperature (K)

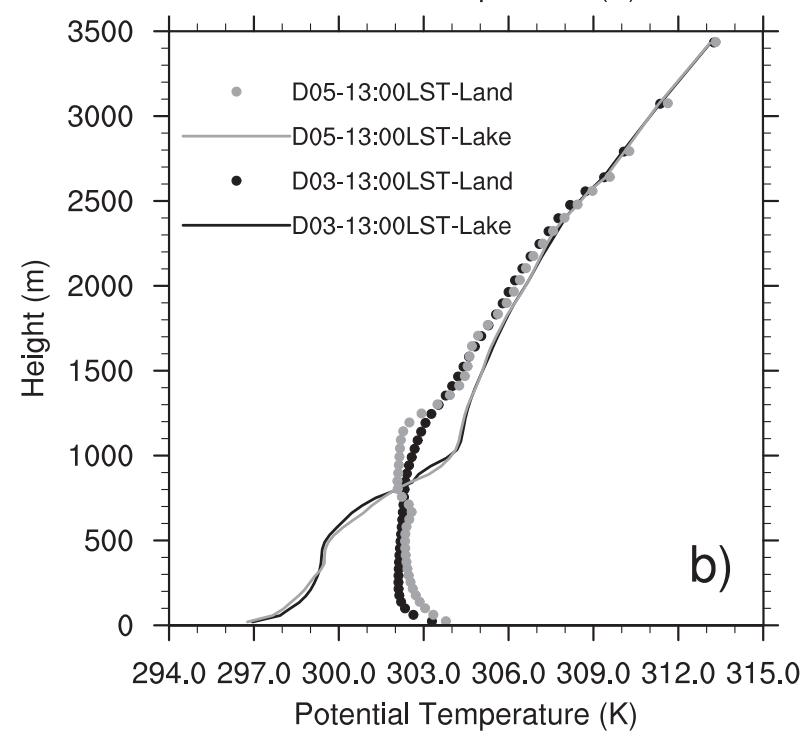

FIG. 10. Subregion average vertical profiles of simulated potential temperature $\theta$ above lake (site A; solid lines) and land (site B; dots) at (a) 0900 LST (0100 UTC) and (b) 1300 LST (0500 UTC) 12 Jun 2012. Sites A and B are indicated in Fig. 4.

terrain to the west of the lake. The model has a similar performance at the northern lakeshore but the lakebreeze wind speed is overpredicted by $0.9-2.9 \mathrm{~m} \mathrm{~s}^{-1}$ in the late afternoon.

The overlay plot of the WRF nested-LES outputs in the innermost domain and the observations at 1300 LST is presented in Fig. 4. The onshore lake breeze was well developed along the shorelines at that time. The WRF nested LES slightly overpredicts the wind speed. The overprediction is partly attributed to underprediction of lake-surface temperature that may enhance lake-land temperature difference. The underprediction of lakesurface temperature will be discussed further in section $3 \mathrm{c}$.
The mean bias (MB) errors for 15 stations of the $U$ and $V$ components of the $10-\mathrm{m}$ wind are 1.69 and $1.30 \mathrm{~m} \mathrm{~s}^{-1}$, respectively, the corresponding root-mean-square errors (RMSE) are 2.01 and $1.59 \mathrm{~m} \cdot \mathrm{s}^{-1}$, and correlation coefficients $C_{r}$ are 0.49 and 0.53 .

Figure 5 shows a comparison of simulated wind vertical profiles with the WPR data at 1400 LST. In general, the model captures the vertical profile patterns of both wind speed and wind direction pretty well, especially between 400 and $1000 \mathrm{~m}$. However, the model fails to reproduce the observed winds near surface. Specifically, the observation shows northerly to northeasterly wind with wind speed up to $4.7 \mathrm{~m} \mathrm{~s}^{-1}$ near the surface, whereas the simulation displays southerly wind with speeds of less than $2.0 \mathrm{~m} \mathrm{~s}^{-1}$. The WPR is positioned in a narrow land surrounded on three sides by lake over the southeastern part of Lake Taihu. The complex local circulations in the lower layer may exert an important impact on wind fields, which helps to explain the large deviation near surface.

Several statistical parameters $\left(C_{r}, \mathrm{MB}\right.$, and RMSE) are calculated to evaluate the model performance at different stages of the lake-breeze evolution. The results show that $C_{r}$ is about 0.25 before 1000 LST, then increases to 0.73 during $1200-1700$ LST, and finally decreases to approximately 0.45 in the following hours. Accordingly, MB (RMSE) decreases from $2.13 \mathrm{~m} \mathrm{~s}^{-1}$ $\left(2.06 \mathrm{~m} \mathrm{~s}^{-1}\right)$ to $1.41 \mathrm{~m} \mathrm{~s}^{-1}\left(1.63 \mathrm{~m} \mathrm{~s}^{-1}\right)$ and then increases to $1.89 \mathrm{~m} \mathrm{~s}^{-1}\left(1.75 \mathrm{~m} \mathrm{~s}^{-1}\right)$. This indicates that the model performs better at the mature stage than at the beginning and dissipation of lake breeze.

Land and lake-surface temperatures retrieved from MODIS satellite measurements are utilized to further assess the WRF nested-LES performance in simulating surface temperature. Several prominent features can be identified from Fig. 6. First, the WRF nested LES is able to capture the spatial distribution pattern of surface temperature presented by MODIS retrieval data (Fig. 4) with lower temperature over lake and higher values over land especially on the northeastern side of the lake. Second, less spatial variability is seen from the retrieved surface temperature mainly because of relatively coarse resolution $(1 \mathrm{~km} \times 1 \mathrm{~km})$. Third, the retrieval data show less land-lake temperature contrast as compared to the simulated values.

Further inspection of the model output shows that the characteristics of the lake breeze vary from one lakeshore to another, depending on the physical properties of the land and the water. Among the physical properties, urban heat island effect and lake-surface temperature are the two important factors. For instance, the maximum depth of the lake-breeze circulation reaches $1.6 \mathrm{~km}$ in the northern lakeshore where the urban heat 

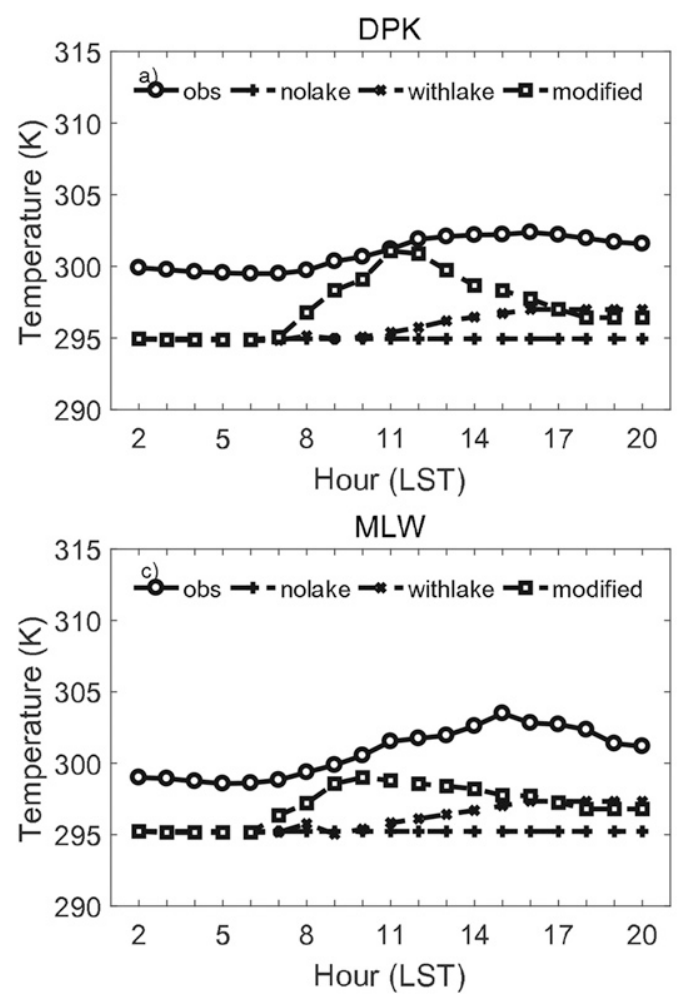

island effect is the most pronounced. This will be discussed further when we examine Fig. 9 below. As a result, the lake breeze at the northern lakeshore is much stronger than at the other shores. In addition, surface temperature differences between different lakeshores are partially attributed to the fact that the large-scale flow direction with respect to the shoreline affects the evolution and inland propagation of lake front (McPherson 1970; Mahrer and Segal 1985; Gilliam et al. 2004).

\section{b. Impact of grid spacing and LES scheme on lake-breeze simulations}

In this section, the simulations between D03 and D05 are compared to examine the impact of grid spacing and LES scheme on lake-breeze simulations: The D05 simulation represents the combined effect of fine grid spacing and LES settings. Figure 7 shows a comparison of the 2-m air temperature at four representative sites. It is clear that the simulated 2-m temperatures in D05 shows much better agreement with observations, especially at the two sites on the eastern and northern lakeshores. The D03 simulation fails to reproduce diurnal pattern of 2-m temperature at these two sites because these two sites are treated as lake rather than land surface. The land use and land cover at other two sites are treated correctly in the simulations. Overall, the D05

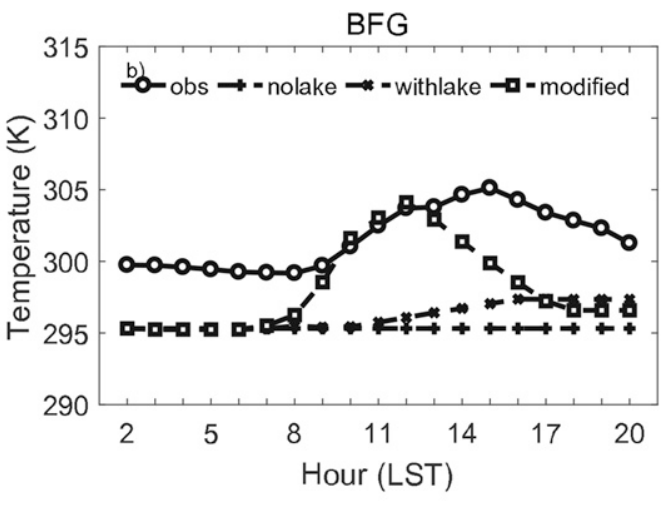

FIG. 11. A comparison of simulated lake-surface temperature from different scenarios and observations at three sites in the lake: (a) DPK, (b) BFG, and (c) MLW (nolake: lake model was turned off; withlake: the lake model was turned on; modified: the lake model was turned on with modified parameters).

simulation shows better agreement with observations than that of D03.

Wind simulations are more challenging. As shown in Fig. 8, the D05 simulation shows better agreement with observations when compared with the D03 simulation. Close examination of $x-y$-plane plots of vertical velocity near the surface (e.g., $100 \mathrm{~m}$ above ground level) shows that the turbulence organized structures (TOSs) can be clearly identified over land in D05 rather than in D03 (figures not shown). TOSs represent an important energy transport mechanism in the boundary layer. The TOSs are well resolved by the simulations at a grid spacing of $150 \mathrm{~m}$ over land but not for over lake. This suggests that the unresolved turbulent motions by coarse grid spacing (e.g., D3 in this study) could be one of the important reasons causing wind prediction biases.

A summary of performance statistics is given in Table 2 to further demonstrate the impact of grid spacing and LES settings on the lake-breeze simulations. Higher $C_{r}$, lower MB, and lower RMSE indicate that the LES run is more successful in capturing temporal and spatial variations of 2-m air temperature and 10-m wind speed. The $C_{r}$ for the $2-\mathrm{m}$ air temperature increases from 0.90 to 0.94 as the grid spacing reduces from $12.15 \mathrm{~km}$ to $150 \mathrm{~m}$, and the MB decreases from 2.5 to $1.8 \mathrm{~K}$ with the corresponding RMSEs reducing from 3.3 to $3.1 \mathrm{~K}$. Decrease in both MB and RMSE from D01 

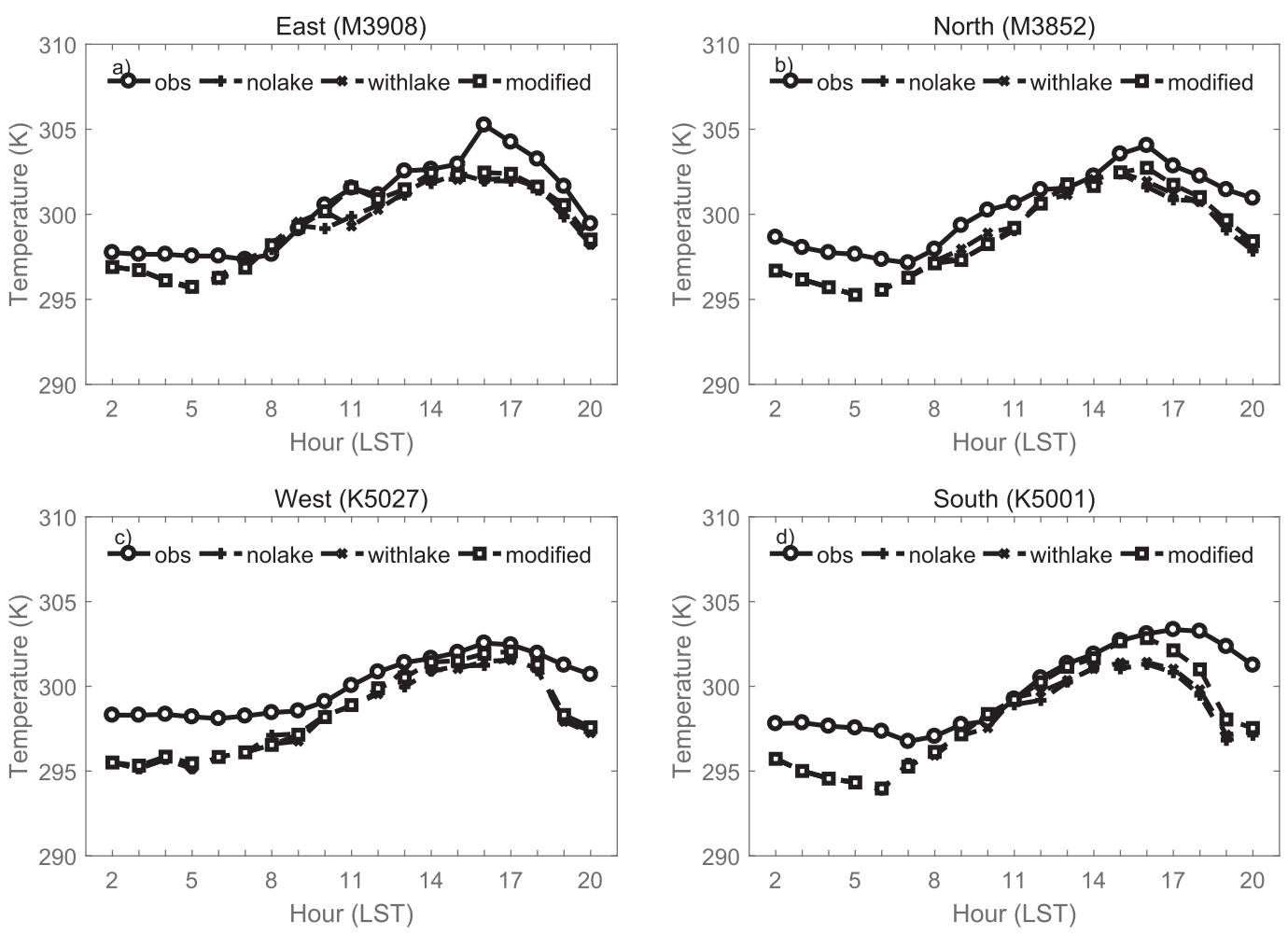

FIG. 12. A comparison of simulated 2-m temperature from different scenarios and observations at four sites on the (a) east (M3908), (b) north (M3852), (c) west (K5027) and (d) south (K5001) sides of the lake (nolake: lake model was turned off; withlake: the lake model was turned on; modified: the lake model was turned on with modified parameter).

to D05 suggests that refined grid spacing improves the wind speed predictions. Generally, the $C_{r}$ values for wind speeds from the standard WRF are low (0.19). Refinement of grid spacing together with LES settings leads to substantial improvement: the $C_{r}$ values for wind speed and $U$ component are increased by $17 \%$ and $34 \%$, respectively, in comparison with those from the standard WRF.

The impact of grid spacing on lake-breeze simulations can be assessed further by examining cross-section plots. Figure 9 shows a comparison of simulated air temperature and relative humidity between D05 and D03 along a transect through the center point of the lake and Wuxi City (Fig. 1) at 1300 LST. Both grid-spacing simulations show similar spatial patterns of potential temperature with warm and stratified layer structures and strong vertical gradient of temperature over the city and weak vertical gradients over the lake. In contrast, the impact of grid spacing on wind simulations is more discernible. The winds simulated with D05 are stronger than those with D03, especially over the city. The thermal circulation in D05 reaches higher vertically and penetrates farther inland than the circulation simulated with D03. Meanwhile, the relative humidity simulated with fine grid spacing displays larger fluctuation than that in D03 simulation.

The modeled lake-breeze depth can be defined as a height at which the horizontal winds shift to offshore flow (Crosman and Horel 2012). As illustrated in Fig. 9, the lake breeze reaches approximately $0.7 \mathrm{~km}$ above the lake and the maximum height of the wind-reverse layer is $1.6 \mathrm{~km}$ above the Wuxi urban area, as a result of the daytime urban heat island effect (UHI, a phenomenon that urban area is significantly warmer than its surroundings). The height of onshore flow is in agreement with the observation near the lake region with a range of 500-600 m (Wang et al. 2017). The stronger low-level onshore flow is limited to the nearshore areas.

Figure 10 shows a comparison of the vertical potential temperature $\theta$ profile simulated using two grid spacings (D03 and D05) over the lake and land areas at 0900 LST (before lake-breeze onset) and 1300 LST (mature stage). The simulated $\theta$ profiles are very different between the lake and the land. The profiles over the lake show a multilayered structure with an inversion at a gradient of $3 \mathrm{~K}$ near the lake surface, and those over the land show structure with a layer with large $\theta$ gradient near surface, a fully mixed layer with constant $\theta$ in the middle, and a 

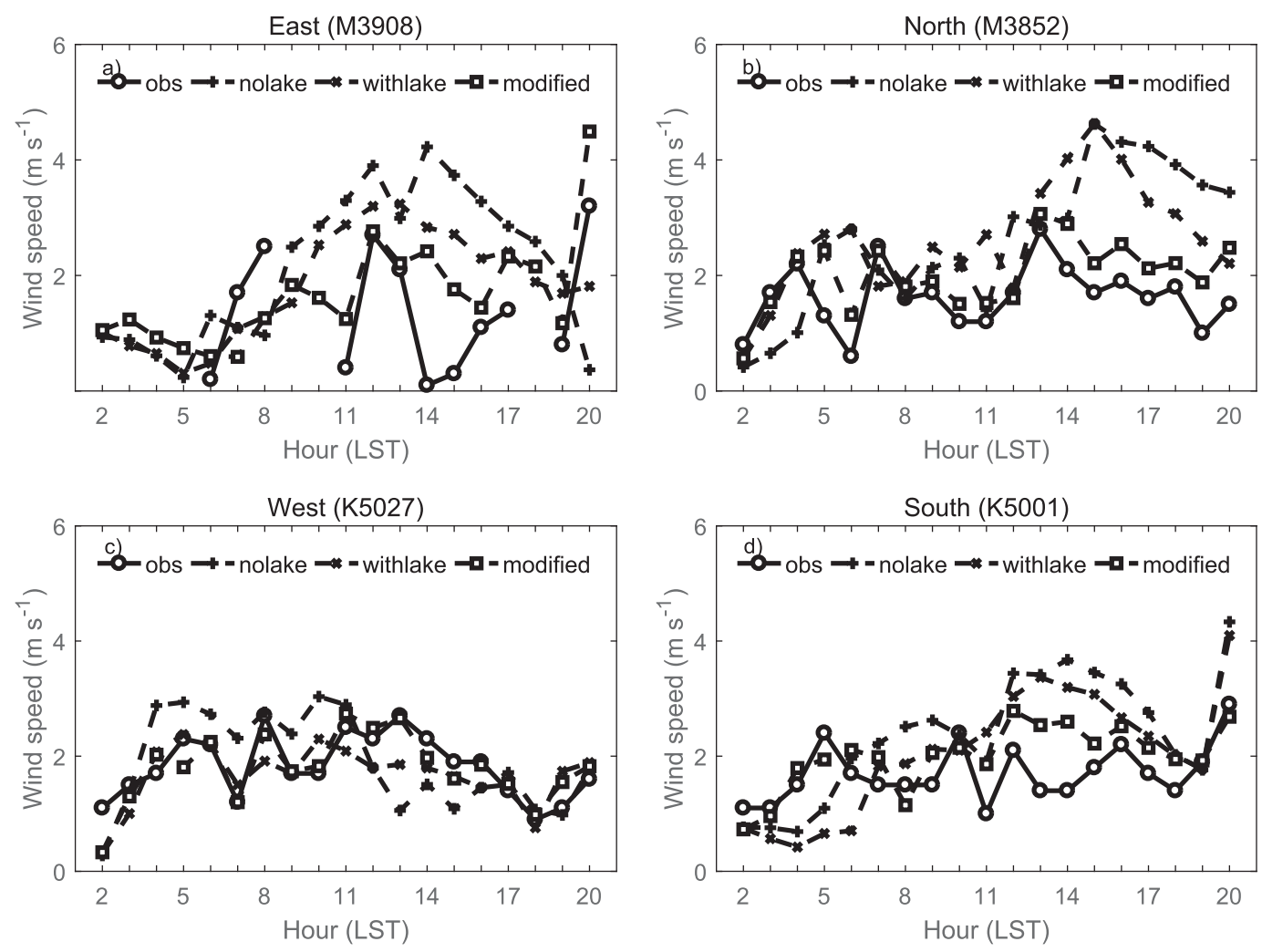

FIG. 13. As in Fig. 12, but for 10-m wind speed.

capping inversion above. The horizontal grid spacing has a noticeable impact on the simulated vertical profiles near surface. The LES results show a stable boundary layer near the lake surface and an unstable boundary layer, driven by higher surface temperature, over the land (Fig. 10a), and a superadiabatic layer. Surprisingly, the inversion strength is stronger at 1300 LST than at 0900 LST even though the lake-surface temperature increases from $295.4 \mathrm{~K}$ at $0900 \mathrm{LST}$ to $296.8 \mathrm{~K}$ at $1300 \mathrm{LST}$. This is because the return flow from the land heats the upper-level air over the lake with a rate higher than the heating rate of the lake-surface air. As the turbulence becomes more vigorous over land, the well-mixed layer fully develops to a height of $1.4 \mathrm{~km}$ by 1300 LST. The simulated $\theta$ vertical profile with fine grid spacing $(150 \mathrm{~m})$ displays a more uniform distribution than that of grid spacing of $1.35 \mathrm{~km}$ within the boundary layer and the three-layered structure is more evident than that with a grid spacing of $1.35 \mathrm{~km}$. The land surface temperature simulated by LES is higher than that simulated by WRF with grid spacing of $1.35 \mathrm{~km}$. The simulated lake breeze tends to be stronger as the grid spacing reduces. As discussed above, the betterresolved eddies in D05 contribute to this change.

Overall, the fine grid spacing with the LES settings produces a more reasonable lake-breeze simulation with more detailed structures than coarse grid spacing with the standard WRF. The ability to produce more details of the lake-breeze circulation makes it easier to analyze the features of the lake breeze, such as upward motion and the maximum lake-breeze height.

\section{c. Impact of lake-surface temperature on lake-breeze simulations}

Lake-surface temperature is critical to improve lakebreeze predictions. In numerical models, this temperature is typically treated as a constant and assigned to the sea surface temperature (SST) from reanalysis data at the same latitude of the lake. However, this treatment may cause large prediction biases for shallow lakes like Lake Taihu. In this section, three sensitivity runs with a lake model are performed to examine the impact of the lake model and thermal eddy diffusivity on simulation results. The three experiments include the cases without lake model (nolake), with default lake model (withlake), and with a modified thermal eddy diffusivity in lake model (modified). In the third run, the eddy diffusivity is reduced to $2 \%$ of the value calculated with the Henderson-Sellers (1985) parameterization according to the work of Deng et al. (2013).

Figure 11 shows a comparison of the simulated lakesurface temperatures with observations at three sites in 

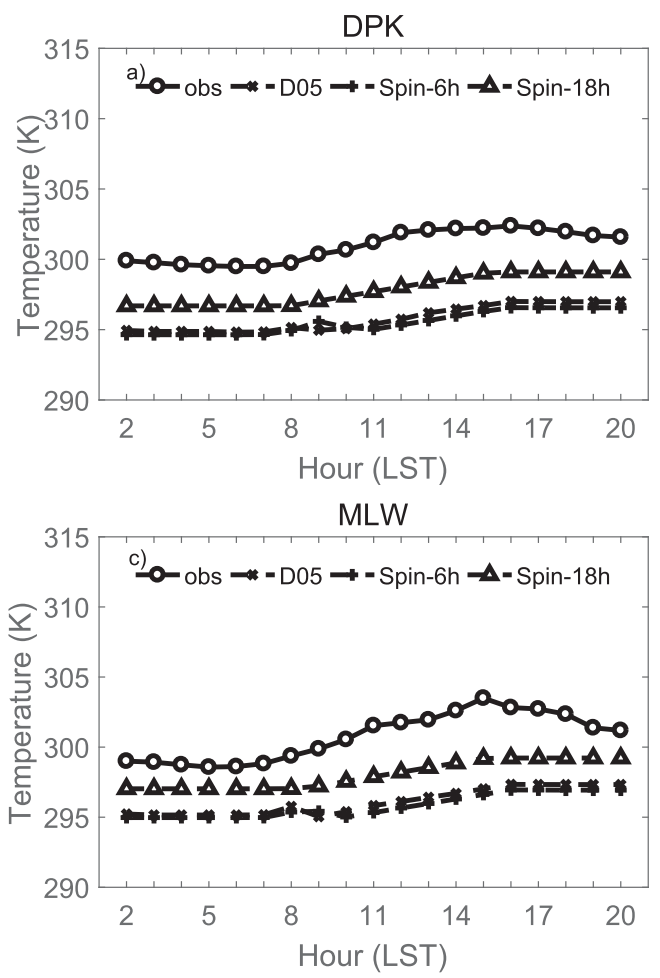

the Lake. Three key points can be found from the figure. First, the run with default parameters used in the lake model shows an increase in lake-surface temperature, but it fails to capture the diurnal variation. This is understandable since all the parameters used in the CLM lake model are mainly developed for being applied for the deep lakes such as the Great Lakes in North America. According to Deng et al. (2013), the thermal eddy diffusivity seems too strong, which leads to substantial underprediction of lake-surface temperature. Second, the diurnal variation is well captured by the lake model when the thermal eddy diffusivity is reduced to $2 \%$ of its default value. However, the time of the maximum lake-surface temperature is shifted by $4 \mathrm{~h}$ (for site $\mathrm{BFG}$ ) or $6 \mathrm{~h}$ (for site MLW) earlier than observations. Third, although the thermal eddy diffusivity is important, it is not the only parameter affecting lake-surface temperature. Other parameters such as water surface thickness and albedo need to be addressed together with the eddy diffusivity for further improvement of lakesurface temperature simulations (Deng et al. 2013). Fourth, initialization of lake-surface temperature with reanalysis SST may cause underpredictions of modelpredicted lake-surface temperature by up to $4.0-5.0 \mathrm{~K}$ at the first six simulation hours, and this could be improved by assimilating available lake-surface temperature observations for generating more realistic initial conditions of lake-surface temperature.

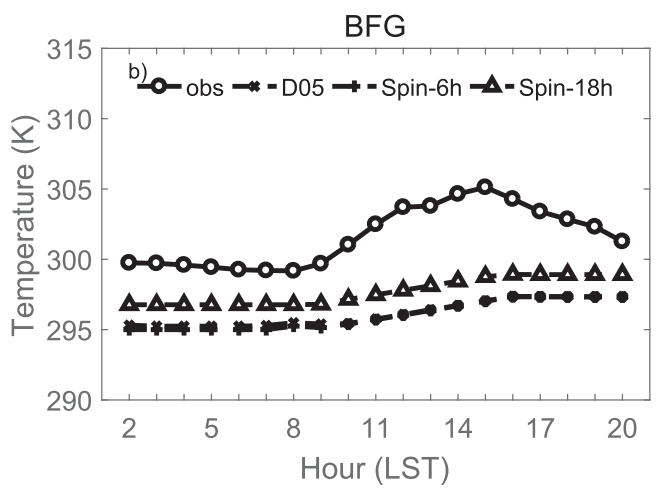

FIG. 14. Time series comparison of simulated lakesurface temperature and observations (obs) for the cases with no spinup (D05), 6-h spinup (label Spin-6h; D05) and 18-h spinup (label Spin-18h; D05) at the (a) DPK, (b) BFG and (c) MLW sites.

The corresponding comparison of 2-m air temperature at four land sites is illustrated in Fig. 12. It is seen that the impact of using a lake model and adjustment of related parameters on air temperature over land is small.

Now let us turn our attention back to the lake-breeze simulations. As shown in Fig. 13, the lake-breeze simulations show a substantial improvement with the thermal eddy diffusivity modified for shallow lake use. The overpredictions are greatly improved at most of the sites along the lakeshores (four sites presented here), and the temporal variation patterns match well with observations. The statistical evaluation shows that, by using the modified thermal eddy diffusivity, $\mathrm{Cr}$ is increased from 0.36 (nolake) to 0.69 for $10-\mathrm{m}$ wind speed and bias is decreased from 1.14 to $0.51 \mathrm{~m} \mathrm{~s}^{-1}$.

\section{Discussion}

Our results show that the simulation of lake breezes can be improved through use of the WRF nested LES and inclusion of a lake model. The improvement is evident in the simulated $2-\mathrm{m}$ air temperature, $10-\mathrm{m}$ wind speed, and vertical profile of potential temperature. However, three points deserve more attention.

First, improvement to potential temperature profile is more evident over the land than over the lake as grid spacing increases. More SFS turbulent eddies resolved 

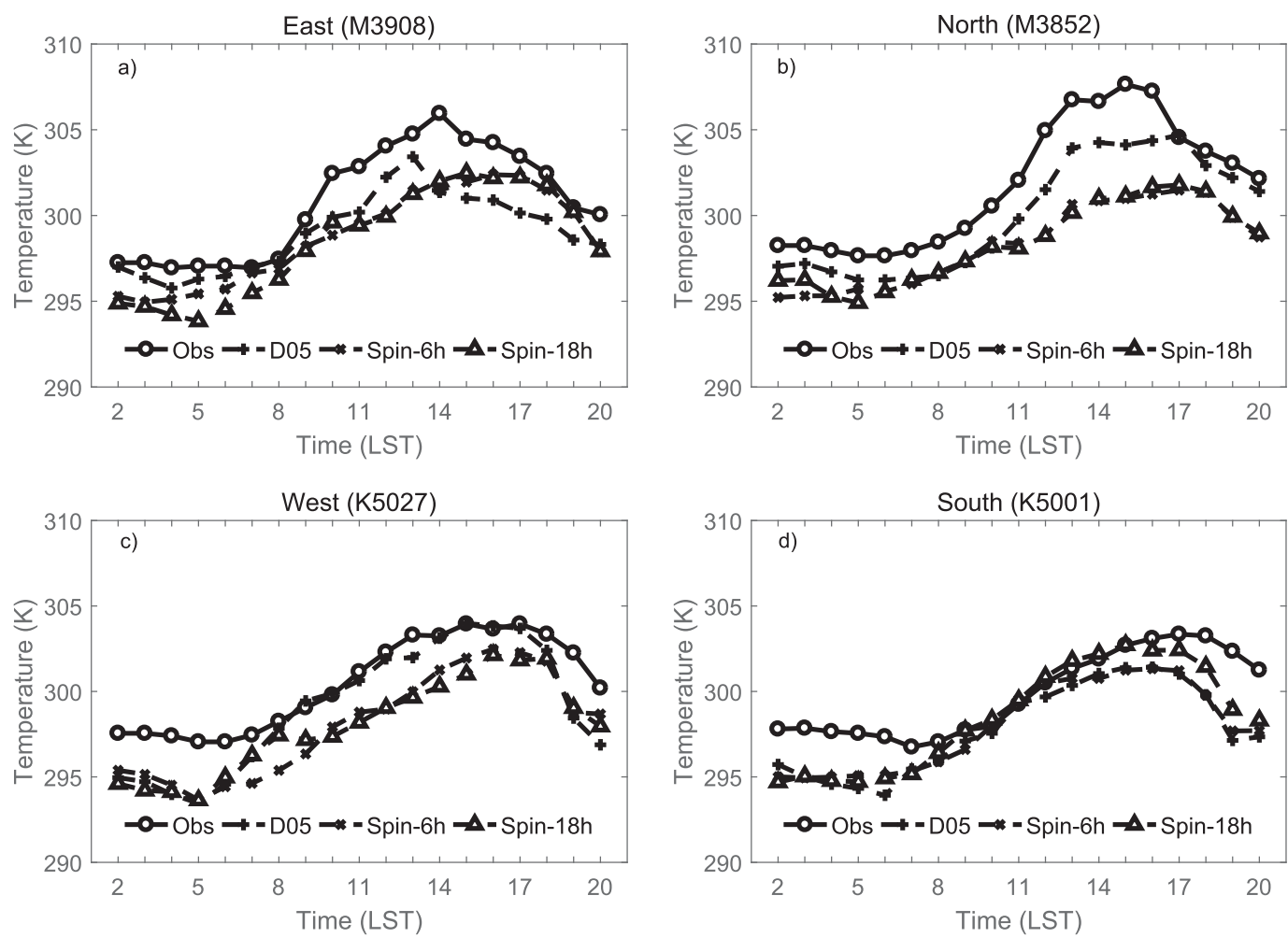

FIG. 15. Time series comparison of simulated 2-m air temperature and observations (Obs) for the cases without spinup (D05), with 6-h spinup (Spin-6h; D05) and with 18-h spinup (Spin-18h; D05) at four sites on the (a) east (M3908), (b) north (M3852), (c) west (K5027), and (d) south (K5001) sides of the lake.

explicitly by the LES with finer grid spacing account for this improvement over the land. In other words, the contribution of SFS to total flux or variance is not well represented by the current PBL parameterization scheme over the land surface where the convective boundary layer is observed. On the other hand, the profiles between D03 and D05 are indistinguishable over the lake where the boundary layer remains stable throughout the lakebreeze evolution. This does not mean that the WRF PBL parameterization scheme performs well for the stable conditions over the lake. It is likely that even a grid spacing of $150 \mathrm{~m}$ is not sufficient to resolve the eddies in the stable boundary layer. An LES with much finer grid spacing may bring further improvement to lake-breeze simulations.

Second, the default parameters used in the CLM V4.5 lake model are not appropriate for shallow lakes. As a type of eddy-diffusion model, the CLM V4.5 lake model requires appropriate setting of various parameters (Oleson et al. 2013; Gu et al. 2015). Among them, thermal eddy diffusivity is a critical parameter in simulating lake-surface temperature. Diurnal variation of lake-surface temperature is better captured by the lake model when thermal eddy diffusivity is reduced by
$98 \%$ from the default value as suggested by Deng et al. (2013). The simulated maximum lake-surface temperature tends to appear much earlier than the observations, however. Adjustment of other parameters related to lake properties such as water surface thickness and albedo in CLM is likely required to better simulate lake-surface temperature (Deng et al. 2013).

Third, increasing spinup time is likely too expensive for improving lake-breeze predictions with the WRF nested LES. To examine this further, two additional simulations were completed with 6 and $18 \mathrm{~h}$ of spinup (given our available computer resources), and the results are presented in Figs. 14-16. As shown in Fig. 14, the positive impact of spinup on lake-surface temperature starts to appear after spinup time is extended to $18 \mathrm{~h}$. The simulated lake-surface temperatures are increased by $1.6-2.0 \mathrm{~K}$ at the three sites in the lake for the scenario with 18 -h spinup run. Thus, it may take a substantial amount of spinup time for the lake model to better capture the observed lake-surface temperature. This perhaps is too expensive for running WRF nested LES with five domains. However, assimilating observed water temperatures in a lake model could be a practical and feasible way to improve lake-surface temperature 

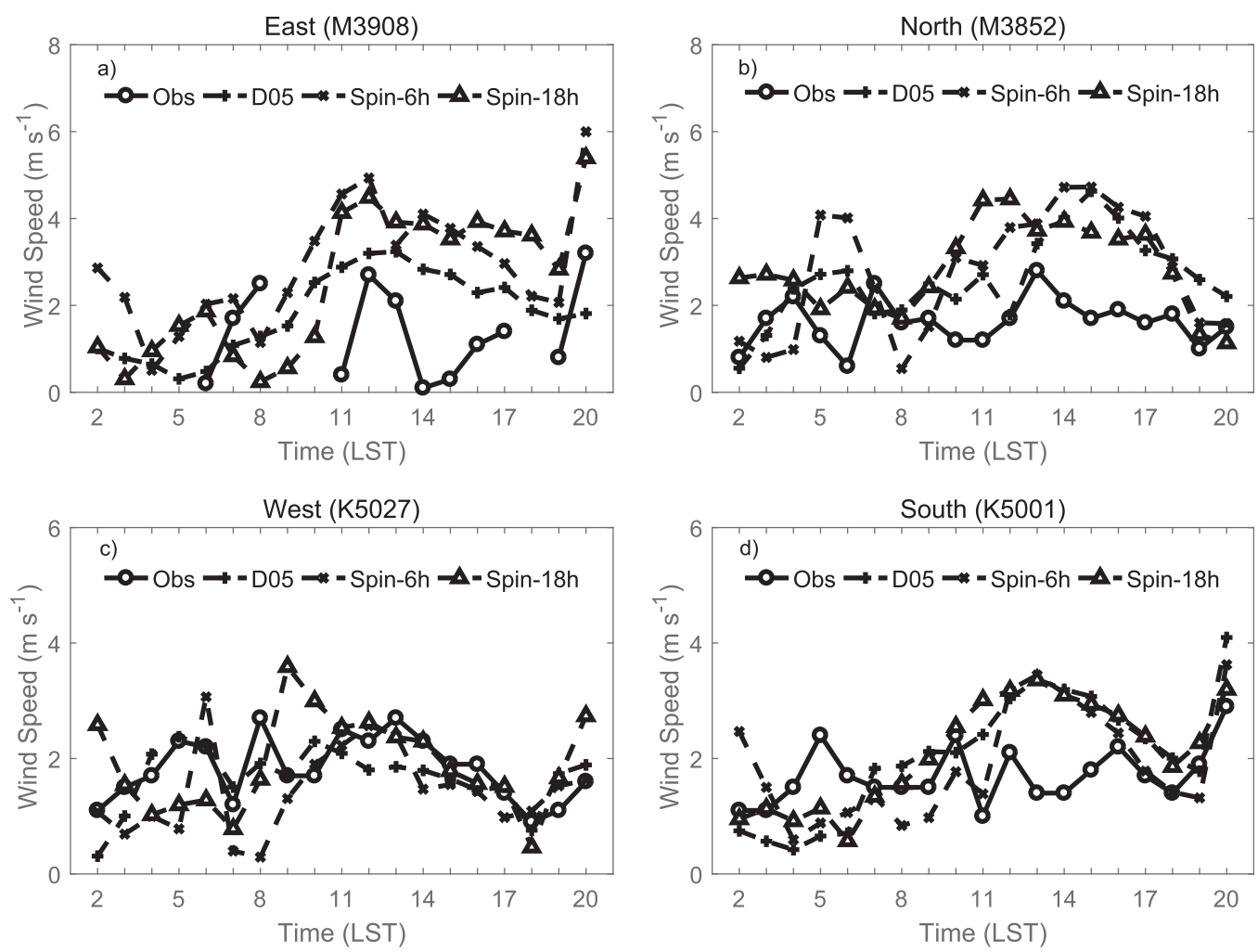

FIG. 16. As in Fig. 15, but for 10-m wind speed.

simulation, which will be investigated separately in another study. Meanwhile, it is noticed that the impact of increased spinup on simulation of 2-m air temperature and $10-\mathrm{m}$ wind speed is limited. These results further demonstrate that multiple efforts are required for further improving lake-breeze simulations.

\section{Conclusions}

A lake-breeze case on 12 June 2012 over Lake Taihu is investigated by using the WRF nested-LES model. Surface measurements obtained from a high-resolution monitoring network are used to evaluate the model performance of $2-\mathrm{m}$ air temperature and $10-\mathrm{m}$ wind. The evaluation results show that the model is able to capture the temporal and spatial variations in these quantities realistically.

The WRF with nested LES at a fine grid spacing of $150 \mathrm{~m}$ improves $2-\mathrm{m}$ temperature and $10 \mathrm{~m}$ wind predictions when compared with its $1.35-\mathrm{km}$ counterpart. The horizontal and vertical circulations are stronger than the results if the $1.35-\mathrm{km}$ WRF setup is used. The fine grid spacing of the LES produces realistic lakebreeze characteristics, such as the maximum lake-breeze height and inland penetration distance. Improvement to vertical profiles of potential temperature is more evident over land than over the lake, indicating that the current planetary boundary layer parameterization scheme likely does not capture unresolved sub-filter-scale turbulent motion accurately over the land surface. It is noted that this conclusion is made based on a comparison between the WRF results in D03 and the WRF nested-LES results in D05, but more observational data are needed to validate this conclusion. Furthermore, the atmospheric boundary layer remains stable throughout the lakebreeze evolution over the lake surface, and the stability tends to be even stronger as the lake breeze reaches its mature stage.

Lake-surface temperature plays a critical role in the lake-breeze predictions. Our numerical experiments indicate that exclusion of the lake model causes an overprediction of lake-breeze wind speed whereas use of a lake model improves the lake-breeze simulations. The lake-surface temperature predictions are improved by using a modified eddy diffusivity, which is necessary for a shallow lake like Lake Taihu (Deng et al. 2013). Some other key lake-property parameters such as water surface thickness and albedo need to be addressed together with thermal eddy diffusivity for further improvement of lake-breeze predictions.

The tests with increased spinup time demonstrate a positive impact on lake-surface temperature predictions. 
It is likely that two or more days of spinup are needed to adjust the initial lake-surface temperature accurately in the lake model when the WRF nested LESs are conducted on multiple-level domains. This might be too expensive for the WRF nested LES with multiple-level domains and very fine grid spacing. Alternatively, constraining water temperatures with observational data for better initialization of the lake model could be another feasible way to improve lake-surface temperature and lake-breeze predictions.

Acknowledgments. The research was supported jointly by the National Natural Science Foundation of China (Grants 91337218, 41575009, and 41275024) and the Xianyang Major Science and Technology Projects (Grant 2017K01-35). The computing for this project was performed at the National Energy Research Scientific Computing Center (NERSC) of the U.S. Department of Energy.

\section{REFERENCES}

Andren, A., A. R. Brown, P. J. Mason, J. Graf, U. Schumann, C. H. Moeng, and F. T. Nieuwstadt, 1994: Large-eddy simulation of a neutrally stratified boundary layer: A comparison of four computer codes. Quart. J. Roy. Meteor. Soc., 120, 1457-1484, https://doi.org/10.1002/qj.49712052003.

Antonelli, M., and R. Rotunno, 2007: Large-eddy simulation of the onset of the sea breeze. J. Atmos. Sci., 64, 4445-4457, https:// doi.org/10.1175/2007JAS2261.1.

Apel, E. C., and Coauthors, 2010: Chemical evolution of volatile organic compounds in the outflow of the Mexico City Metropolitan area. Atmos. Chem. Phys., 10, 2353-2375, https:// doi.org/10.5194/acp-10-2353-2010.

Colby, F. P., 2004: Simulation of the New England sea breeze: The effect of grid spacing. Wea. Forecasting, 19, 277-285, https:// doi.org/10.1175/1520-0434(2004)019<0277:SOTNES>2.0.CO;2.

Comer, N. T., and I. G. McKendry, 1993: Observations and numerical modelling of Lake Ontario breezes. Atmos.-Ocean, 31, 481-499, https://doi.org/10.1080/07055900.1993.9649482.

Crosman, E. T., and J. D. Horel, 2010: Sea and lake breezes: A review of numerical studies. Bound.-Layer Meteor., 137, 1-29, https://doi.org/10.1007/s10546-010-9517-9.

$\longrightarrow$, and — 2012: Idealized large-eddy simulations of sea and lake breezes: Sensitivity to lake diameter, heat flux and stability. Bound.-Layer Meteor., 144, 309-328, https://doi.org/ 10.1007/s10546-012-9721-x.

Dabberdt, W. F., and Coauthors, 2004: Meteorological research needs for improved air quality forecasting: Report of the 11th Prospectus Development Team of the U.S. Weather Research Program. Bull. Amer. Meteor. Soc., 85, 563-586, https:// doi.org/10.1175/BAMS-85-4-563.

Dandou, A., M. Tombrou, and N. Soulakellis, 2009: The influence of the city of Athens on the evolution of the sea-breeze front. Bound.-Layer Meteor., 131, 35-51, https://doi.org/10.1007/ s10546-008-9306-x.

Deng, B., S. Liu, W. Xiao, W. Wang, J. Jin, and X. Lee, 2013: Evaluation of the CLM4 lake model at a large and shallow freshwater lake. J. Hydrometeor., 14, 636-649, https://doi.org/ 10.1175/JHM-D-12-067.1.
Dudhia, J., 1989: Numerical study of convection observed during the winter monsoon experiment using a mesoscale two-dimensional model. J. Atmos. Sci., 46, 3077-3107, https://doi.org/10.1175/ 1520-0469(1989)046<3077:NSOCOD>2.0.CO;2.

Fovell, R. G., 2005: Convective initiation ahead of the sea-breeze front. Mon. Wea. Rev., 133, 264-278, https://doi.org/10.1175/ MWR-2852.1.

Freitas, E. D., C. M. Rozoff, W. R. Cotton, and P. L. S. Dias, 2007: Interactions of an urban heat island and sea-breeze circulations during winter over the metropolitan area of São Paulo, Brazil. Bound.-Layer Meteor., 122, 43-65, https://doi.org/ 10.1007/s10546-006-9091-3.

Gilliam, R. C., S. Raman, and D. D. S. Niyogi, 2004: Observational and numerical study on the influence of large-scale flow direction and coastline shape on sea-breeze evolution. Bound.-Layer Meteor., 111, 275-300, https://doi.org/10.1023/ B:BOUN.0000016494.99539.5a.

Green, B. W., and F. Zhang, 2015: Numerical simulations of Hurricane Katrina (2005) in the turbulent gray zone. J. Adv. Model. Earth Syst., 7, 142-161, https://doi.org/10.1002/ 2014MS000399.

Gronewold, A. D., V. Fortin, B. Lofgren, A. Clites, C. A. Stow, and F. Quinn, 2013: Coasts, water levels, and climate change: A Great Lakes perspective. Climatic Change, 120, 697-711, https://doi.org/10.1007/s10584-013-0840-2.

Gu, H., J. Jin, Y. Wu, M. B. Ek, and Z. M. Subin, 2015: Calibration and validation of lake surface temperature simulations with the coupled WRF-lake model. Climatic Change, 129, 471-483, https://doi.org/10.1007/s10584-013-0978-y.

Hanley, K. E., R. S. Plant, T. H. M. Stein, R. J. Hogan, J. C. Nicol, H. W. Lean, C. Halliwell, and P. A. Clark, 2015: Mixing-length controls on high-resolution simulations of convective storms. Quart. J. Roy. Meteor. Soc., 141, 272-284, https://doi.org/ 10.1002/qj.2356.

Heath, N. K., H. E. Fuelberg, S. Tanelli, F. J. Turk, R. P. Lawson, S. Woods, and S. Freeman, 2017: WRF nested large-eddy simulations of deep convection during SEAC ${ }^{4}$ RS. J. Geophys. Res. Atmos., 122, 3953-3974, https://doi.org/10.1002/2016JD025465.

Henderson-Sellers, B., 1985: New formulation of eddy diffusion thermocline models. Appl. Math. Model., 9, 441-446, https:// doi.org/10.1016/0307-904X(85)90110-6.

Hong, S. Y., J. Dudhia, and S. H. Chen, 2004: A revised approach to ice microphysical processes for the bulk parameterization of clouds and precipitation. Mon. Wea. Rev., 132, 103-120, https://doi.org/ 10.1175/1520-0493(2004)132<0103:ARATIM >2.0.CO;2.

_, Y. Noh, and J. Dudhia, 2006: A new vertical diffusion package with an explicit treatment of entrainment processes. Mon. Wea. Rev., 134, 2318-2341, https://doi.org/10.1175/MWR3199.1.

Hostetler, S. W., and P. J. Bartlein, 1990: Simulation of lake evaporation with application to modeling lake level variations of Harney-Malheur Lake, Oregon. Water Resour. Res., 26 , 2603-2612, https://doi.org/10.1029/WR026i010p02603.

Hu, X. M., J. W. Nielsen-Gammon, and F. Zhang, 2010: Evaluation of three planetary boundary layer schemes in the WRF model. J. Appl. Meteor. Climatol., 49, 1831-1844, https://doi.org/ 10.1175/2010JAMC2432.1.

Kain, J. S., and J. M. Fritsch, 1993: Convective parameterization for mesoscale models: The Kain-Fritsch scheme. The Representation of Cumulus Convection in Numerical Models, meteor. monogr., No. 46, Amer. Meteor. Soc., 165-170, https://doi.org/ 10.1007/978-1-935704-13-3_16.

Kala, J., T. J. Lyons, D. J. Abbs, and U. S. Nair, 2010: Numerical simulations of the impacts of land-cover change on a southern 
sea breeze in south-west Western Australia. Bound.-Layer Meteor., 135, 485-503, https://doi.org/10.1007/s10546-010-9486-z.

Keen, C. S., and W. A. Lyons, 1978: Lake/land breeze circulations on the western shore of Lake Michigan. J. Appl. Meteor., 17, 1843-1855, https://doi.org/10.1175/1520-0450(1978)017<1843: LBCOTW $>2.0 . \mathrm{CO} ; 2$.

Kehler, S., J. Hanesiak, M. Curry, D. Sills, and N. Taylor, 2016: High Resolution Deterministic Prediction System (HRDPS) simulations of Manitoba lake breezes. Atmos.-Ocean, 54, 93 107, https://doi.org/10.1080/07055900.2015.1137857.

Khairoutdinov, M. F., S. K. Krueger, C. H. Moeng, P. A. Bogenschutz, and D. A. Randall, 2009: Large-eddy simulation of maritime deep tropical convection. J. Adv. Model. Earth Syst., 1 (15), https://doi.org/10.3894/JAMES.2009.1.15.

Kosović, B., 1997: Subgrid-scale modelling for the large-eddy simulation of high-Reynolds-number boundary layers. J. Fluid Mech., 336, 151-182, https://doi.org/10.1017/S0022112096004697.

Laird, N. F., D. A. Kristovich, X. Z. Liang, R. W. Arritt, and K. Labas, 2001: Lake Michigan lake breezes: Climatology, local forcing, and synoptic environment. J. Appl. Meteor., 40, 409-424, https://doi.org/10.1175/1520-0450(2001)040<0409: LMLBCL $>2.0$. CO;2.

Lambert, S., 1974: A high resolution numerical study of the seabreeze front. Atmosphere, 12, 97-105, https://doi.org/10.1080/ 00046973.1974 .9648375 .

Lawrence, D. M., and Coauthors, 2010: Parameterization improvements and functional and structural advances in version 4 of the Community Land Model. J. Adv. Model. Earth Syst., 3, 365-375, https://doi.org/10.1029/2011MS00045.

Lee, X., and Coauthors, 2014: The Taihu eddy flux network: an observational program on energy, water, and greenhouse gas fluxes of a large freshwater lake. Bull. Amer. Meteor. Soc., 95, 1583-1594, https://doi.org/10.1175/BAMS-D-13-00136.1.

Lyons, W. A., 1972: The climatology and prediction of the Chicago lake breeze. J. Appl. Meteor., 11, 1259-1270, https://doi.org/ 10.1175/1520-0450(1972)011<1259:TCAPOT>2.0.CO;2.

Mahrer, Y., and M. Segal, 1985: On the effects of islands' geometry and size on inducing sea breeze circulation. Mon. Wea. Rev., 113, 170-174, https://doi.org/10.1175/1520-0493(1985) $113<0170$ :OTEOIG $>2.0$. CO 2 .

Mariani, Z., A. Dehghan, P. Joe, and D. Sills, 2018: Observations of lake-breeze events during the Toronto 2015 Pan-American Games. Bound.-Layer Meteor., 166, 113-135, https://doi.org/ 10.1007/s10546-017-0289-3.

McNider, R., and Coauthors, 2018: Examination of the physical atmosphere in the Great Lakes region and its potential impact on air quality-Overwater stability and satellite assimilation. J. Appl. Meteor. Climatol., 57, 2789-2816, https://doi.org/ 10.1175/JAMC-D-17-0355.1.

McPherson, R. D., 1970: A numerical study of the effect of a coastal irregularity on the sea breeze. J. Appl. Meteor., 9, 767-777, https://doi.org/10.1175/1520-0450(1970)009<0767: ANSOTE $>2.0 . \mathrm{CO} ; 2$.

Mirocha, J. D., J. K. Lundquist, and B. Kosović, 2010: Implementation of a nonlinear subfilter turbulence stress mode for large-eddy simulation in the Advanced Research WRF model. Mon. Wea. Rev., 138, 4212-4228, https://doi.org/10.1175/ 2010MWR3286.1.

Mlawer, E. J., S. J. Taubman, P. D. Brown, M. J. Iacono, and S. A. Clough, 1997: Radiative transfer for inhomogeneous atmospheres: RRTM, a validated correlated $k$ model for the longwave. J. Geophys. Res., 102,16 663-16 682, https://doi.org/ 10.1029/97JD00237.
Moeng, C. H., 1984: A large-eddy-simulation model for the study of planetary boundary-layer turbulence. J. Atmos. Sci., 41, 2052-2062, https://doi.org/10.1175/1520-0469(1984)041<2052: ALESMF $>2.0 . \mathrm{CO} ; 2$

J. Dudhia, J. Klemp, and P. Sullivan, 2007: Examining twoway grid nesting for large eddy simulation of the PBL using the WRF model. Mon. Wea. Rev., 135, 2295-2311, https://doi.org/ 10.1175/MWR3406.1

Nieuwstadt, F. T., P. J. Mason, C. H. Moeng, and U. Schumann, 1993: Large-eddy simulation of the convective boundary layer: A comparison of four computer codes. Turbulent Shear Flows 8 , Springer, 343-367.

Oleson, K. W., and Coauthors, 2004: Technical description of the Community Land Model (CLM). NCAR Tech. Note NCAR/TN-461+STR, 173 pp., https://doi.org/10.5065/ D6N877R0.

—_ and Coauthors, 2010: Technical description of version 4.0 of the Community Land Model (CLM). NCAR Tech. Note NCAR/TN-478+STR, 257 pp., https://doi.org/10.5065/ D6FB50WZ.

_, and Coauthors, 2013: Technical description of version 4.5 of the Community Land Model (CLM). NCAR Tech. Note NCAR/TN-503+STR, 420 pp., https://doi.org/10.5065/ D6RR1W7M.

Pearce, R. P., 1955: The calculation of a sea-breeze circulation in terms of the differential heating across the coastline. Quart. J. Roy. Meteor. Soc., 81, 351-381, https://doi.org/10.1002/ qj. 49708134906

Rao, P. A., H. E. Fuelberg, and K. K. Droegemeier, 1999: Highresolution modeling of the Cape Canaveral area land-water circulations and associated features. Mon. Wea. Rev., 127, 1808-1821, https://doi.org/10.1175/1520-0493(1999)127<1808: HRMOTC $>2.0 . \mathrm{CO} ; 2$

Rao, Y. R., N. Hawley, and C. W. M. Schertzer, 2008: Physical processes and hypoxia in the central basin of Lake Erie. Limnol. Oceanogr., 53, 2007-2020, https://doi.org/10.4319/ lo.2008.53.5.2007.

Segal, M., and R. A. Pielke, 1985: The effect of water temperature and synoptic winds on the development of surface flows over narrow, elongated water bodies. J. Geophys. Res., 90, $4907-$ 4910, https://doi.org/10.1029/JC090iC03p04907.

Sills, D. M. L., J. R. Brook, I. Levy, P. A. Makar, J. Zhang, and P. A. Taylor, 2011: Lake breezes in the southern Great Lakes region and their influence during BAQS-Met 2007. Atmos. Chem. Phys., 11, 7955-7973, https://doi.org/10.5194/ acp-11-7955-2011.

Smagorinsky, J., 1963: General circulation experiments with the primitive equations: I. The basic experiment. Mon. Wea. Rev., 91, 99-164, https://doi.org/10.1175/1520-0493(1963)091<0099: GCEWTP>2.3.CO;2.

Stein, T. H., R. J. Hogan, K. E. Hanley, J. C. Nicol, H. W. Lean, R. S. Plant, P. A. Clark, and C. E. Halliwell, 2014: The three-dimensional morphology of simulated and observed convective storms over southern England. Mon. Wea. Rev., 142, 3264-3283, https://doi.org/10.1175/MWR-D-1300372.1.

Stull, R. B., 1988: An Introduction to Boundary Layer Meteorology. Kluwer Academic, 666 pp.

Talbot, C., P. Augustin, C. Leroy, V. Willart, H. Delbarre, and G. Khomenko, 2007: Impact of a sea breeze on the boundarylayer dynamics and the atmospheric stratification in a coastal area of the North Sea. Bound.-Layer Meteor., 125, 133-154, https://doi.org/10.1007/s10546-007-9185-6. 
Thompson, W. T., T. Holt, and J. Pullen, 2007: Investigation of a sea breeze front in an urban environment. Quart. J. Roy. Meteor. Soc., 133, 579-594, https://doi.org/10.1002/qj.52.

Wang, Y., and Coauthors, 2017: Spatiotemporal characteristics of lake breezes over Lake Taihu, China. J. Appl. Meteor. Climatol., 56, 2053-2065, https://doi.org/10.1175/JAMCD-16-0220.1.

Wong, J., M. C. Barth, and D. Noone, 2013: Evaluating a lightning parameterization based on cloud-top height for mesoscale numerical model simulations. Geosci. Model Dev., 6, 429-443, https://doi.org/10.5194/gmd-6-429-2013.

Zhang, Y., Y. L. Chen, T. A. Schroeder, and K. Kodama, 2005: Numerical simulations of sea-breeze circulations over northwest Hawaii. Wea. Forecasting, 20, 827-846, https://doi.org/ 10.1175/WAF859.1.

Zhu, P., B. A. Albrecht, V. P. Ghate, and Z. Zhu, 2010: Multiplescale simulations of stratocumulus clouds. J. Geophys. Res., 115, D23201, https://doi.org/10.1029/2010JD014400. 